\title{
Electrophysiological Properties of Rostral Ventrolateral Medulla Presympathetic Neurons Modulated by the Respiratory Network in Rats
}

\author{
Davi J. A. Moraes, Melina P. da Silva, Leni G. H. Bonagamba, André S. Mecawi, Daniel B. Zoccal, \\ José Antunes-Rodrigues, Wamberto A. Varanda, and Benedito H. Machado \\ Department of Physiology, School of Medicine of Ribeirão Preto, University of São Paulo, 14049-900, Ribeirão Preto, SP, Brazil
}

\begin{abstract}
The respiratory pattern generator modulates the sympathetic outflow, the strength of which is enhanced by challenges produced by hypoxia. This coupling is due to the respiratory-modulated presympathetic neurons in the rostral ventrolateral medulla (RVLM), but the underlining electrophysiological mechanisms remain unclear. For a better understanding of the neural substrates responsible for generation of this respiratory-sympathetic coupling, we combined immunofluorescence, single cell qRT-pCR, and electrophysiological recordings of the RVLM presympathetic neurons in in situ preparations from normal rats and rats submitted to a metabolic challenge produced by chronic intermittent hypoxia $(\mathrm{CIH})$. Our results show that the spinally projected cathecholaminergic $\mathrm{C} 1$ and non-C1 respiratory-modulated RVLM presympathetic neurons constitute a heterogeneous neuronal population regarding the intrinsic electrophysiological properties, respiratory synaptic inputs, and expression of ionic currents, albeit all neurons presented persistent sodium current-dependent intrinsic pacemaker properties after synaptic blockade. A specific subpopulation of non-C1 respiratory-modulated RVLM presympathetic neurons presented enhanced excitatory synaptic inputs from the respiratory network after CIH. This phenomenon may contribute to the increased sympathetic activity observed in $\mathrm{CIH}$ rats. We conclude that the different respiratory-modulated RVLM presympathetic neurons contribute to the central generation of respiratory-sympathetic coupling as part of a complex neuronal network, which in response to the challenges produced by $\mathrm{CIH}$ contribute to respiratory-related increase in the sympathetic activity.
\end{abstract}

Key words: bulbospinal RVLM presympathetic neurons; chronic intermittent hypoxia; intrinsic electrophysiological properties; respiratory-sympathetic coupling

\section{Introduction}

Oscillations in the sympathetic outflow are modulated by the respiratory rhythm in rats (Numao et al., 1987; Haselton and Guyenet, 1989) and humans (Badra et al., 2001; Dempsey et al., 2002), and this modulation contributes to the neurogenic vasomotor tone (Bachoo and Polosa, 1985). This phenomenon is in part a consequence of activation of pulmonary stretch receptors (Zhou et al., 2002). However, the respiratory modulation of sympathetic activity persist even after vagotomy (Adrian et al., 1932; Barman and Gebber, 1980; Haselton and Guyenet, 1989), suggesting the existence of a central neural coupling between the respiratory pattern generator and the neurons involved with the generation of the sympathetic activity. The strength of this respiratory-sympathetic coupling is enhanced by challenges,

Received July 17, 2013; revised 0ct. 23, 2013; accepted 0ct. 28, 2013.

Author contributions: D.J.M., D.B.Z., and B.H.M. designed research; D.J.M., M.P.d.S., L.G.B., and A.S.M. performed research; D.J.M., M.P.d.S., L.G.B., A.S.M., J.A.-R., W.A.V., and B.H.M. analyzed data; D.J.M., M.P.d.S., W.A.V., and B.H.M. wrote the paper.

This work was supported by Fundação de Amparo à Pesquisa do Estado de São Paulo (FAPESP; grant to B.H.M.2009/50113-0, grant to W.A.V. - 2012/19750-7, and a postdoctoral fellowship to D.J.A.M., 2011/24050-1) and a CAPES fellowship grant to M.P.d.S.

Correspondence should be addressed to Dr. Davi J. A. Moraes, Department of Physiology, School of Medicine of Ribeirão Preto, University of São Paulo, 14049-900, Ribeirão Preto, SP, Brazil. E-mail: davimoraes@rfi.fmrp.usp.br. DOI:10.1523/JNEUROSCI.3041-13.2013

Copyright $\odot 2013$ the authors $\quad 0270-6474 / 13 / 3319223-15 \$ 15.00 / 0$ such as acute (Dick et al., 2004), chronic hypoxia (Zoccal et al., 2008; Moraes et al., 2012a) and increased respiratory drive (Malpas, 1998; Taylor et al., 1999) to provide a fine tuning in the cardiovascular and respiratory responses under these circumstances.

It has been suggested that the neuronal coupling between the respiratory and sympathetic activities occurs, at least in part, at the level of the rostral ventrolateral medulla (RVLM), where the bulbospinal presympathetic neurons are located (Reis et al., 1989; Guyenet et al., 1990; Dampney, 1994). This brainstem region contains two major groups of presympathetic bulbospinal glutamatergic neurons: one expresses all enzymes required for production of adrenaline ( $\mathrm{C} 1$ group) and the other correspond to noncatecholaminergic neurons (Ruggiero et al., 1994; Stornetta et al., 2002). Most of the bulbospinal RVLM presympathetic neurons have a respiratory-related modulation of their activity (Terui et al., 1986; McAllen, 1987; Haselton and Guyenet, 1989; Miyawaki et al., 1995).

Despite the existence of a large body of electrophysiological evidence, from both extracellular (Guyenet and Brown, 1986; Morrison et al., 1988; Haselton and Guyenet, 1989; Kanjhan et al., 1995) and intracellular recordings (Dembowsky and McAllen, 1990; Lipski et al., 1995a,b, 1996; Zagon and Spyer, 1996) in anesthetized animals, several fundamental aspects such as (1) 


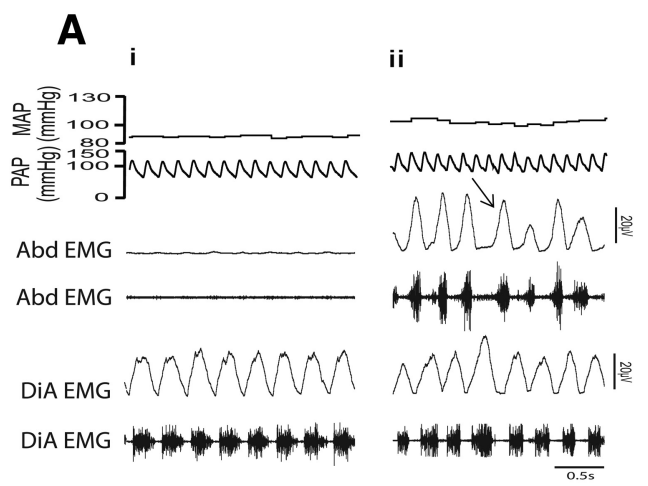

B

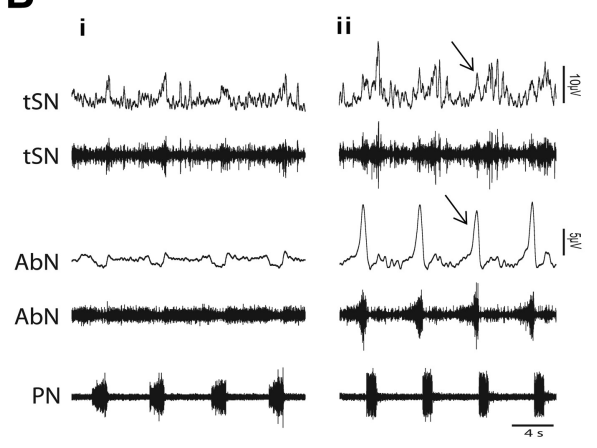

Figure 1. Recordings of arterial pressure, respiratory muscles, and nerves in vivo and in situ preparations of control and CIH rats. Raw and integrated $\left(\int\right)$ EMG records of inspiratory (diaphragm-DiA), expiratory muscles (abdominal-Abd) simultaneously with pulsatile arterial pressure (PAP) and mean arterial pressure (MAP) in conscious, freely moving rats from control (Ai) and $\mathrm{CIH}(\boldsymbol{A i i})$ rats. Note the presence of late-expiration (late-E) activity in the $\mathrm{Abd}(\uparrow)$ and the increase in the MAP after $\mathrm{ClH}$. Raw and integrated $\left(\int\right)$ records of thoracic sympathetic nerve $(\mathrm{tSN})$, abdominal nerve (AbN), and phrenic nerve (PN) activities of in situ preparations from the same control and $\mathrm{CIH}$ rats shown in $\boldsymbol{A i}(\boldsymbol{B i})$ and in $\boldsymbol{A i i}$ (Bii), respectively. Note the presence of late-E event $(\uparrow)$ in the $\mathrm{SSN}$ and $\mathrm{AbN}$ after $\mathrm{ClH}$.

their respiratory-related synaptic inputs; (2) their relation to $\mathrm{C1}$ group of neurons; and (3) their intrinsic electrophysiological properties, remain unclear. Therefore, in the present study we used whole-cell patch recordings, in unanaesthetized preparations with preserved networks, to get a better understanding of the modulation of bulbospinal RVLM presympathetic neurons induced by respiratory network. Experiments were performed using the in situ working heart-brainstem preparation (Paton, 1996) to evaluate the respiratory-related synaptic inputs, the pacemaker activity, the different ionic currents, and membrane properties of the respiratory-modulated RVLM presympathetic neurons in normal rats and in rats submitted to a metabolic challenge produced by chronic intermittent hypoxia $(\mathrm{CIH})$.

Our results show that the respiratory-modulated RVLM presympathetic neurons constitute a heterogeneous neuronal population, regarding the intrinsic electrophysiological properties, respiratory synaptic inputs, relation to $\mathrm{C} 1$ group of neurons, as well in the control of sympathetic outflow in response to a metabolic challenge produced by $\mathrm{CIH}$.

\section{Materials and Methods}

Animals and ethical approval. Experiments were performed on male Wistar rats (85-140 g) obtained from the Animal Care Facility of the University of São Paulo, Ribeirão Preto, Brazil. The animals were maintained in standard environmental conditions $\left(23 \pm 2^{\circ} \mathrm{C} ; 12 / 12 \mathrm{~h}\right.$ dark/ light cycle) with water and chow ad libitum. All experimental protocols were approved by the Ethical Committee on Animal Experimentation of
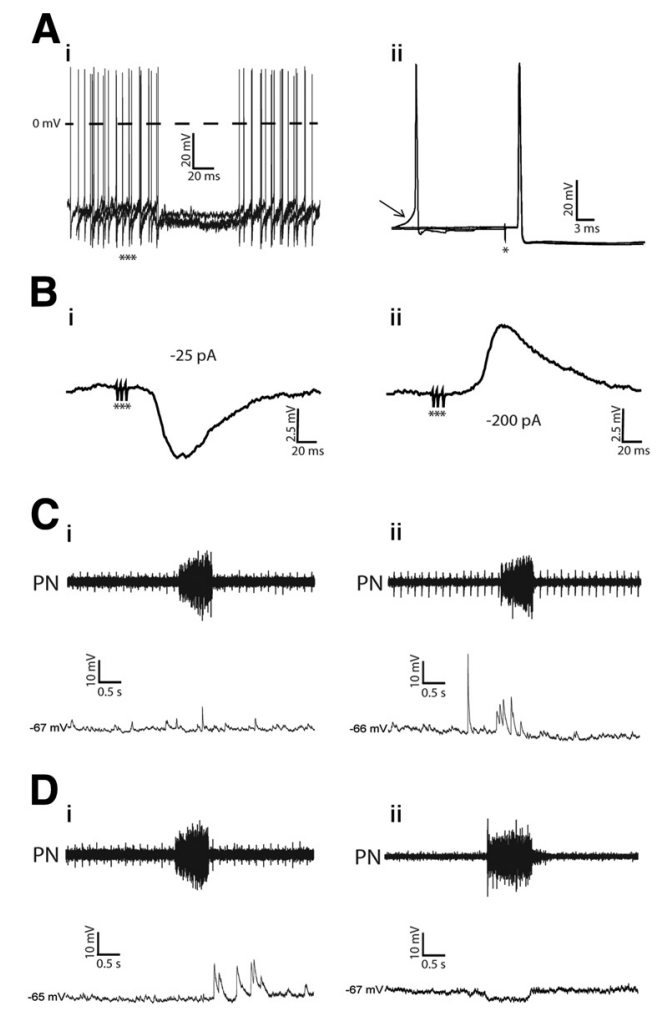

Figure 2. Electrophysiological identification of the nonmodulated and respiratorymodulated RVLM presympathetic neurons in in situ preparations. Ai, Hyperpolarizing potentials and inhibition of spike discharge frequency (3 superimposed sweeps, no polarizing current, membrane potential, $-57 \mathrm{mV}$ ) evoked by stimulation of the ipsilateral ADN with bursts of 3 pulses $\left({ }^{* *}\right)$. Aii, Antidromic action potentials evoked by stimulation $\left(^{*}\right)$ of the T8-T12 segment of the spinal cord. Three superimposed sweeps pretriggered by sEPSPs are shown. The arrow indicates spontaneous excitatory postsynaptic potential preceding spontaneous spikes. Note that spinal stimulation was followed by antidromic responses that occurred $\sim 6 \mathrm{mV}$ more negative than the threshold at which spontaneous action potentials were induced by the ongoing synaptic activity. Bi, The ADN-evoked potentials (10 averaged sweeps) recorded intracellularly when the firing of the cell was stopped by a continuous negative current ( $-25 \mathrm{pA})$. Bii, Reversal of evoked inhibitory postsynaptic potential (holding current of $-200 \mathrm{pA}$ ) evoked by stimulation of the ADN. Ci-Dii, sEPSPs, measured by hyperpolarizing the neurons, in the nonmodulated (Ci), inspiratory-modulated (Cii), postinspiratory modulated (Di), and inspiratoryinhibited (Dii) RVLM presympathetic neurons.

the School of Medicine of Ribeirão Preto, University of São Paulo (protocols \#093/2009 and \#064/2010).

Chronic intermittent hypoxia. The $\mathrm{CIH}$ and control groups of rats were housed in collective cages and maintained in Plexiglas chambers (volume, $210 \mathrm{~L}$ ) equipped with gas injectors of $\mathrm{O}_{2}$ and $\mathrm{CO}_{2}$ and sensors of $\mathrm{O}_{2}$, $\mathrm{CO}_{2}$, humidity, and temperature. The $\mathrm{CIH}$ group was exposed to $5 \mathrm{~min}$ of normoxia (fraction of inspired $\mathrm{O}_{2}, \mathrm{FiO}_{2}$, of $20.8 \%$ ) followed by $4 \mathrm{~min}$ of $\mathrm{N}_{2}$ injection to reduce the $\mathrm{FiO}_{2}$ from 20.8 to $6 \%$, remaining at this level between 30 and 40 s. After hypoxia, $\mathrm{O}_{2}$ was injected to return $\mathrm{FiO}_{2}$ back to $20.8 \%$. This cycle with duration of 9 min was repeated over the time of $8 \mathrm{~h}$ a day (from 9:30 A.M. to 5:30 P.M.) for $10 \mathrm{~d}$. During the remaining $16 \mathrm{~h}$, the animals were exposed to $20.8 \% \mathrm{FiO}_{2}$. Control rats were exposed to $20.8 \% \mathrm{FiO}_{2} 24 \mathrm{~h}$ a day for $10 \mathrm{~d}$ as described in a previous study from our laboratory (Zoccal et al., 2008).

Respiratory and cardiovascular measurements in conscious animals. Electromyogram (EMG) of respiratory muscles were used to evaluate inspiration and expiration index in freely behaving conditions after submitting the animal to the hypoxic $(n=16)$ or normoxic $(n=13)$ protocols. Two days before starting these protocols, rats were anesthetized with tribromoethanol (250 mg.kg-1, i.p.; Aldrich) and bipolar Tefloncoated stainless steel EMG electrodes were implanted in the diaphragm (DIA) and abdominal muscles (Abd). Wires were tunneled under the skin and attached to an electrical socket positioned on the back of the 
A

i

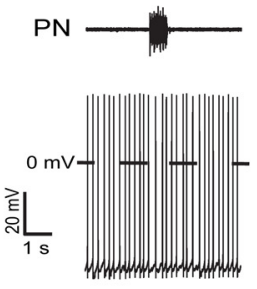

B

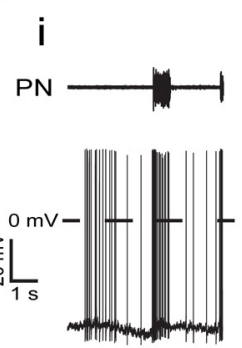

C<smiles>[H]</smiles>

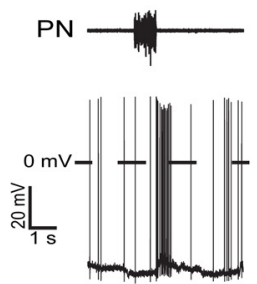

D

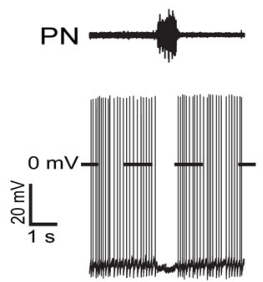

ii

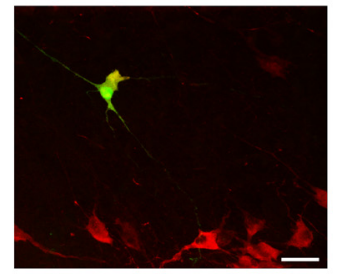

ii

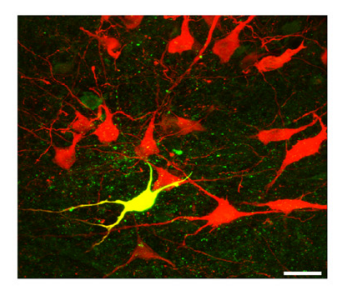

ii

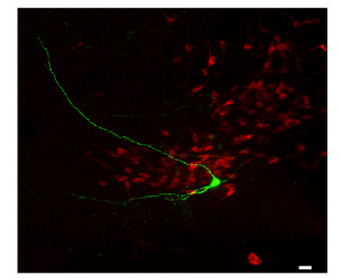

ii

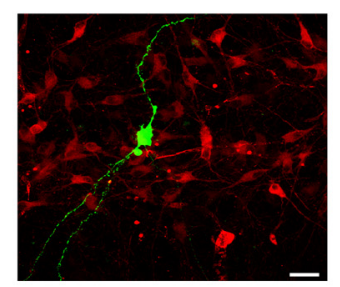

iii

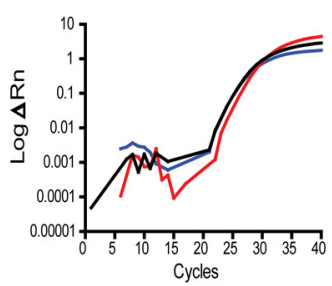

iii

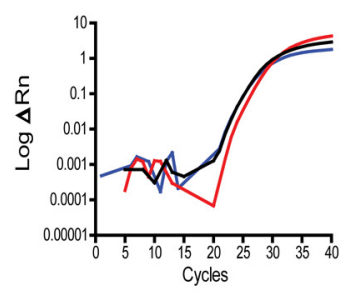

iii

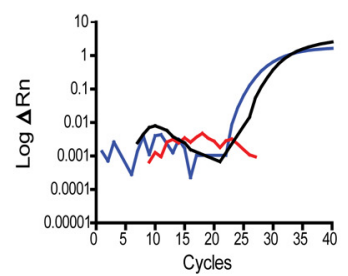

iii

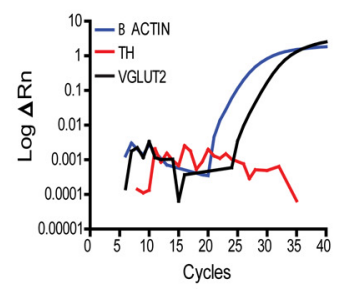

Figure 3. Phenotype of the nonmodulated and respiratory-modulated RVLM presympathetic neurons. Ai-Aii, Representative voltage traces of one nonmodulated RVLM presympathetic neuron (Ai) and the corresponding photomicrograph (Aii) showing biocytin (green) and TH (red) immunohistochemical staining. Note that this RVLM presympathetic neuron is a positive TH-ir cell (yellow). Aiii, Amplification plots of TH, VGLUT 2 , and $\beta$ actin from qRT-PCR from another nonmodulated RVLM presympathetic neuron. The fluorescent emission ( $\triangle \mathrm{RN})$ is plotted against the number of cycles. Note that this neuron expresses $\mathrm{TH}$ and also VGLUT 2 . Bi-Bii, Representative voltage traces of one inspiratory-modulated RVLM presympathetic neuron (Bi) and the corresponding photomicrograph (Bii) showing biocytin (green) and TH (red) immunohistochemical staining. Note that this RVLM presympathetic neuron is also a positive TH-ir cell (yellow). Biii, Amplification plots of TH, VGLUT ${ }_{2}$, and $\beta$ actin from qRT-PCR from another inspiratory-modulated RVLM presympathetic neuron. Note that this neuron expresses TH and also VGLUT 2 . Ci-Cii, Representative voltage traces of one postinspiratory-modulated RVLM presympathetic neuron $(\boldsymbol{C} i)$ and the corresponding photomicrograph (Cii) showing biocytin (green) and TH (red) immunohistochemical staining. Note that this RVLM presympathetic neuron is a negative TH-ir cell. Ciii, Amplification plots of TH, VGLUT, and $\beta$ actin from qRT-PCR from another postinspiratory-modulated RVLM presympathetic neuron. Note that this neuron does not express TH but expresses VGLUT 2 . Di-Dii, Representative voltage traces of one inspiratory-inhibited RVLM presympathetic neuron (Di) and the corresponding photomicrograph (Dii) showing biocytin (green) and TH (red) immunohistochemical staining. Note that this RVLM presympathetic neuron is also a negative TH-ir cell. Diiii, Amplification plots of TH, VGLUT 2 , and $\beta$ actin from qRT-PCR from another inspiratory-inhibited RVLM presympathetic neuron. Note that this neuron does not express TH but expresses VGLUT 2 . Scale bar, $20 \mu \mathrm{m}$.

rat's neck. At the end of the experimental protocol (CIH or normoxia), rats were anesthetized with tribromoethanol and a catheter was inserted into the abdominal aorta through the femoral artery for arterial pressure measurement ( $n=39$; control: 13 rats with and 6 rats without EMG measurements; $\mathrm{CIH}$ : 16 rats with and 4 rats without EMG measure- ments). The catheter was tunneled subcutaneously and exteriorized through the skin in the back of the rat's neck. One day after, the arterial catheter was connected to a pressure transducer, and in turn, to an amplifier (Bridge Amp, ML221, ADInstruments). The electrical socket of the EMG was also connected to an amplifier (Bioamplifier, Insight). The arterial pressure and EMG $(0.5-5 \mathrm{kHz}$ of bandpass) signals were acquired by a data acquisition system (CED 1401, Cambridge Electronic Design) controlled by a computer running the software Spike 2 (Cambridge Electronic Design, CED). The respiratory and cardiovascular parameters were recorded in conscious, freely moving rats under normoxic conditions during $60 \mathrm{~min}$.

Ventral approach in the working heart-brainstem preparation. Immediately after recordings in freely behaving conditions $(n=39)$ or after submitting the animal to the control $(n=67)$ or $\mathrm{CIH}$ protocols $(n=26)$, the rats were prepared for an in situ working heart-brainstem preparation, as previously described (Paton, 1996). Briefly, the animals were deeply anesthetized with halothane (AstraZeneca), transected caudal to the diaphragm, exsanguinated, and submerged in icecold artificial CSF (ACSF) containing the following (in mM): $125 \mathrm{NaCl}, 24 \mathrm{NaHCO}_{3}, 3 \mathrm{KCl}$, $2.5 \mathrm{CaCl}_{2}, 1.25 \mathrm{MgSO}_{4}, 1.25 \mathrm{KH}_{2} \mathrm{PO}_{4}, 10 \mathrm{dex}-$ trose. They were then decerebrated at the precollicular level, therefore rendered insentient and skinned. To expose the ventral medullary surface for neuronal recordings, the preparations were placed supine and all muscles and connective tissues covering the basilar surface of occipital bone were removed. Then, the basilar portion of the occipital bone was removed to expose the ventral surface of the medulla in the anteroposterior extension from the vertebral arteries to the pontine nuclei as previously described (Moraes et al., 2012b). Preparations were then transferred to a recording chamber and the descending aorta was cannulated and retrogradely perfused with ACSF containing an oncotic agent (1.25\% Polyethylene glycol, Sigma), a neuromuscular blocker (vecuronium bromide, 3-4 $\mu \mathrm{g} / \mathrm{ml}$, Cristália Produtos Químicos Farmacêuticos), and continuously gassed with $5 \% \mathrm{CO}_{2}$ and $95 \% \mathrm{O}_{2}$ using a peristaltic pump (Watson-Marlow 502s). For voltageclamp experiments of isolated T-type calcium currents, the ACSF consisted (in mM): $118 \mathrm{NaCl}$, $3 \mathrm{KCl}, 1 \mathrm{MgSO}_{4}, 24 \mathrm{NaHCO}_{3}, 1 \mathrm{NaH}_{2} \mathrm{PO}_{4}, 1.5$ $\mathrm{CaCl}_{2}, 10$ dextrose. The perfusate was warmed to $31-32^{\circ} \mathrm{C}$ and filtered using a nylon mesh (pore size: $25 \mu \mathrm{m}$, Millipore).

Electrophysiological measurements. Sympathetic and phrenic nerves were isolated and their activities recorded using bipolar glass suction electrodes. Phrenic nerve (PN) activity was recorded from its central end. The activity of thoracic sympathetic nerve (tSN) was recorded from the sympathetic chain at the level of T8-T12. All signals were amplified, bandpass filtered (Bioamplifier, Insight; $0.5-5 \mathrm{kHz}$ ), and acquired with an A/D converter (CED 1401, Cambridge Electronic Design, CED) controlled by a computer running Spike 2 software (Cambridge Electronic Design, CED).

Blind whole-cell patch-clamp recordings were obtained from medullary RVLM presympathetic neurons (one neuron per rat) with electrodes 
Table 1. Average values of electrophysiological properties of nonmodulated and all respiratory-modulated RVLM presympathetic neurons recorded from control and CIH rats

\begin{tabular}{|c|c|c|c|c|c|c|c|c|}
\hline & \multicolumn{4}{|l|}{ Control } & \multicolumn{4}{|l|}{$\mathrm{ClH}$} \\
\hline & Group I $(n=9)$ & Group II $(n=12)$ & Group III $(n=12)$ & Group IV $(n=12)$ & Group I $(n=10)$ & Group II $(n=12)$ & Group III $(n=14)$ & Group IV $(n=10)$ \\
\hline Capacitance (pF) & $39 \pm 1.9$ & $36 \pm 1.7$ & $40 \pm 1.8$ & $42 \pm 1.8$ & $40 \pm 3.6$ & $41.5 \pm 2.8$ & $38 \pm 2.7$ & $40 \pm 1.2$ \\
\hline Frequency (Hz) & $6 \pm 1.1$ & $22 \pm 3^{*}$ & $13 \pm 2$ & $8 \pm 1.9$ & $6.4 \pm 2.2$ & $20 \pm 2.4$ & $15 \pm 3.1$ & $9 \pm 2$ \\
\hline $\mathrm{RMP}(\mathrm{mV})$ & $-53 \pm 2.2$ & $-51 \pm 2.3$ & $-52 \pm 3.2$ & $-54 \pm 3.4$ & $-52 \pm 4$ & $-50 \pm 2$ & $-53 \pm 2.1$ & $-53 \pm 2$ \\
\hline$R_{\mathrm{i}}(\mathrm{M} \Omega)$ & $335 \pm 1.1^{* *}$ & $162 \pm 6.5^{\#}$ & $245 \pm 5^{\# \#}$ & $515 \pm 9$ & $348 \pm 8$ & $159 \pm 7$ & $259 \pm 5$ & $509 \pm 16.6$ \\
\hline Excitability (spikes) & $46 \pm 6^{* *}$ & $90 \pm 8.7^{+}$ & $61 \pm 7$ & $64 \pm 6$ & $49 \pm 6$ & $95 \pm 7.7$ & $59 \pm 6.7$ & $74 \pm 5$ \\
\hline $\mathrm{AHP}(\mathrm{mV})$ & $7 \pm 1.1^{\# \# \#}$ & $3 \pm 0.6$ & $3.3 \pm 0.7$ & $6 \pm 1.3$ & $7.2 \pm 2.2$ & $2.8 \pm 0.9$ & $3 \pm 0.9$ & $6.2 \pm 2.3$ \\
\hline
\end{tabular}

Excitability: values in response to injection of $100 \mathrm{pA}$ of positive current. ${ }^{*} p<0.05$ different in relation to groups I, III, and IV from control rats; ${ }^{* *} p<0.001$ different in relation to the groups II, III, and IV from control rats; ${ }^{\#} p<0.001$ different in relation to the groups III and IV from control rats; ${ }^{\# \# ~} p<0.001$ different in relation to the group IV from control rats; ${ }^{\# \# \#} p<0.05$ different in relation to the groups II and III from control rats; ${ }^{+} p<0.05$ different in relation to the group III from control rats. CIH produced no changes in the electrophysiological properties of the $4 \mathrm{groups}$ of RVLM presympathetic neurons characterized, and the differences among the groups in CIH were also similar to those observed in neurons from control rats.

filled with a solution containing the following (in $\mathrm{mM}$ ): $130 \mathrm{~K}$-gluconate, $4.5 \mathrm{MgCl}_{2} ; 14$ trisphosphocreatine, 10 HEPES; 5 EGTA; 4 NaATP; 0.3 Na-GTP; $0.2 \%$ biocytin; $\mathrm{pH} 7.3$, and $\sim 300 \mathrm{mOsmol}$ and had resistances of 3-8 M $\Omega$ when tested in bath solution. Only for voltageclamp experiments of T-type calcium currents, the electrodes were filled with a solution containing the following (in $\mathrm{mm}$ ): $110 \mathrm{CsCl}_{2}, 30$ TEA, $1 \mathrm{CaCl}_{2}$, 5 EGTA, $2 \mathrm{MgCl}_{2}$, 4 Na-ATP, 0.5 Na-GTP, 10 HEPES, $\mathrm{pH} 7.3$, and $\sim 300$ mOsmol. The electrodes were mounted on a micromanipulator (MHW-3; Narishige) and positioned onto the ventral surface of the medulla under visual control (binocular microscope; Zeiss) using surface landmarks (trapezoid body, rootlets of the hypoglossal nerve, and basilar artery) and coordinates of RVLM presympathetic neurons for orientation as previously described (Moraes et al., 2012b). The RVLM presympathetic neurons were also characterized by its inhibitory response to baroreflex activation (by electrically stimulating either contralateral or ipsilateral aortic depressor nerves-ADN; $0.2 \mathrm{~ms}$, 3 pulses at $400 \mathrm{~Hz}$ ) and the presence of antidromic responses to stimulation of spinal segment T8-T12 (0.2 ms). Antidromic responses were distinguished from synaptic excitation by using near threshold stimulation of descending axons, and at this intensity of stimulation synaptic events were absent (absence of spontaneous excitatory postsynaptic potential preceding evoked spikes). Voltage- and current-clamp experiments were performed using an Axopatch200B integrating amplifier (Molecular Devices) and pClamp acquisition software (version 10.0, Molecular Devices). Gigaseals ( $>1 \mathrm{G} \Omega$ ) were formed, and whole-cell configuration was obtained by suction. Recordings with access resistance larger than $20 \mathrm{M} \Omega$ were not used.

Ionic currents were measured under voltageclamp with the cell's membrane potential initially held at $-70 \mathrm{mV}$ and expressed as $\mathrm{pA} / \mathrm{pF}$ to normalize for cells of different sizes. Activation properties of outward transient potassium current (IA) were evaluated by applying $10 \mathrm{mV}$ voltage steps ( $2 \mathrm{~s}$ ) from -80 to $60 \mathrm{mV}$, from conditioning step (500 ms) of either -110 or $-40 \mathrm{mV}$. After off-line subtraction of the currents evoked with holding voltage of -110 and $-40 \mathrm{mV}$, the IA current was isolated. To maximize IA and reduce sodium currents, TTX (0.5 $\mu \mathrm{M}$; Tocris Bioscience) was added to the perfusion solution. The voltage-dependent inactivation of IA was estimated using conditioning steps
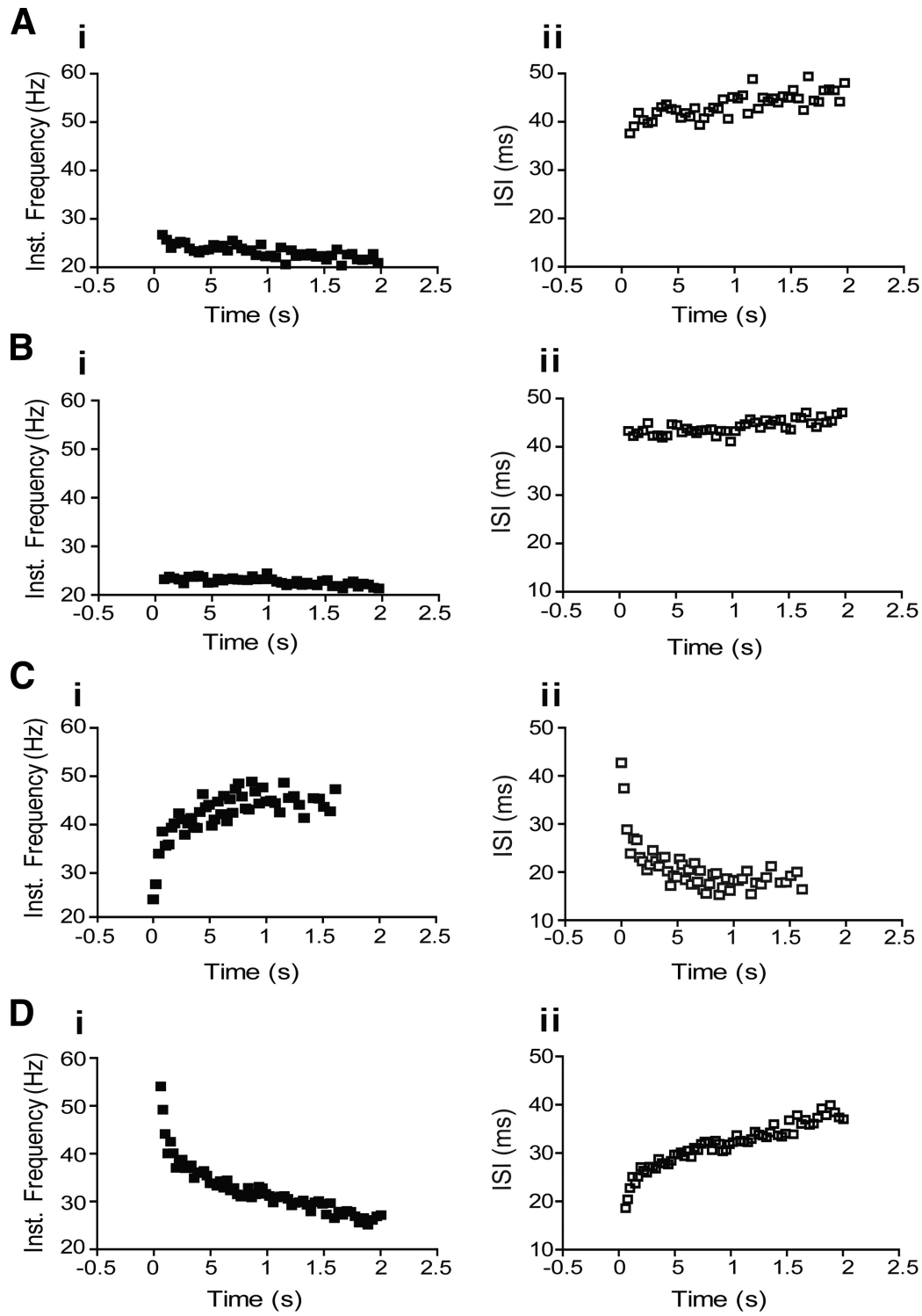

Figure 4. Repetitive firing properties of nonmodulated and respiratory-modulated RVLM presympathetic neurons from control rats. Plots of representative traces of instantaneous spike discharge frequency versus time and interspike interval (ISI) versus time obtained from representative control nonmodulated (Ai, Aii), inspiratory-modulated (Bi, Bii), postinspiratory-modulated (Ci, Cii), and inspiratory-inhibited (Di, Dii) RVLM presympathetic neurons in response to injection of $100 \mathrm{pA}$ of positive current.

of $1 \mathrm{~s}$ ranging from -130 to $-30 \mathrm{mV}$ in $10 \mathrm{mV}$ increments followed by a test pulse of $500 \mathrm{~ms}$ to $-30 \mathrm{mV}$. To measure subthreshold sodium-persistent conductance $\left(I_{\mathrm{NaP}}\right), 30 \mathrm{mV} / \mathrm{s}$ ramp from -85 to $15 \mathrm{mV}$ were applied. The riluzole-sensitive (10 $\mu \mathrm{M}$; Tocris Bioscience) component of the ramp- 
A
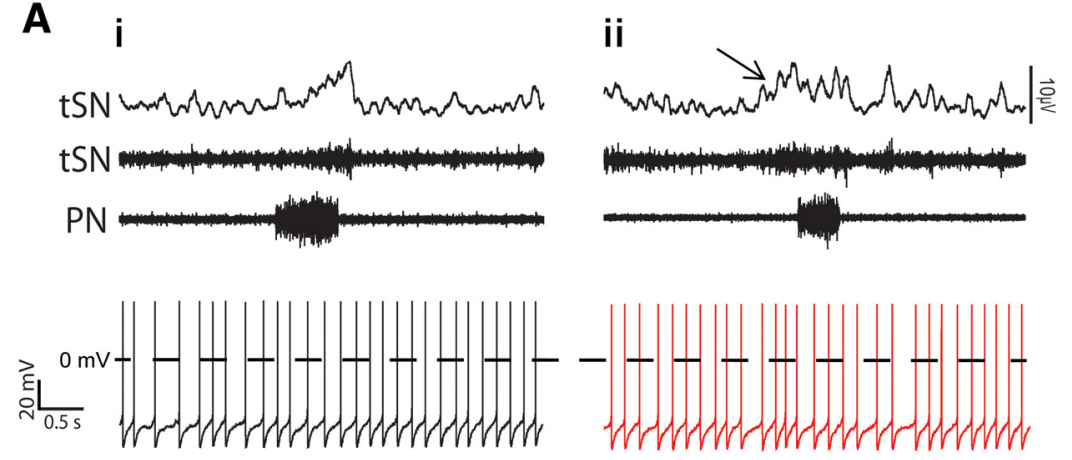

B
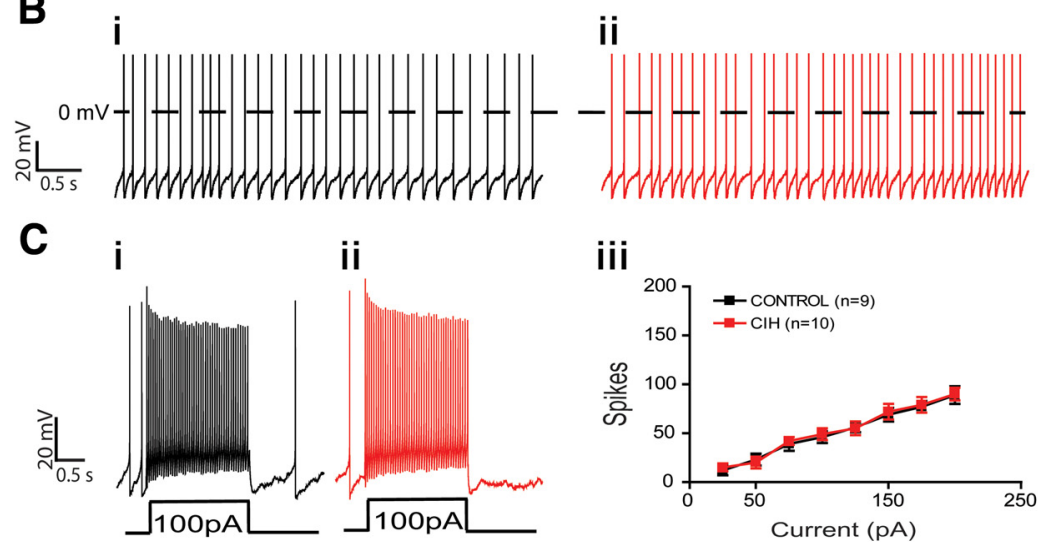

iii

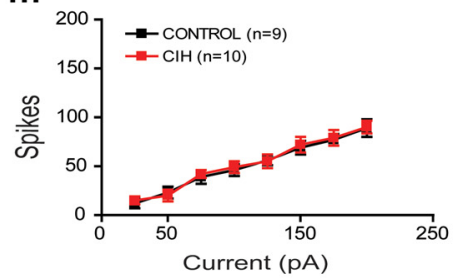

D
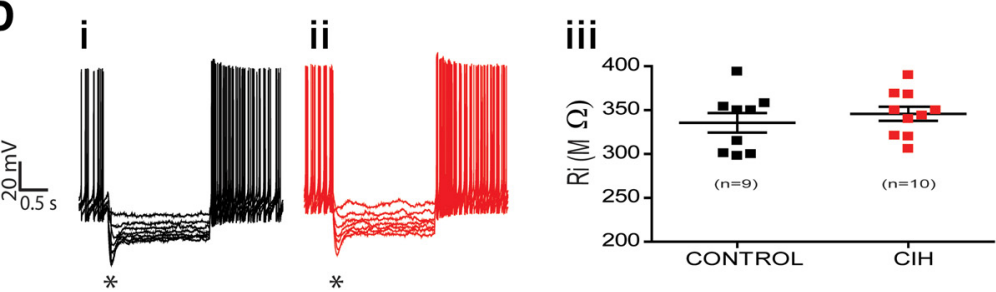

Figure 5. Spike discharge frequency and intrinsic electrophysiological properties of nonmodulated RVLM presympathetic neurons from control and $\mathrm{CIH}$ rats. Raw and integrated $\left(\int\right)$ records of $\mathrm{PN}, \mathrm{TSN}$, and nonmodulated RVLM presympathetic neurons activities from control (Ai) and (IH (Aii) rats. Note the presence of late-expiration (late-E; $\uparrow$ ) in tSN and no changes in the spike discharge frequency of nonmodulated RVLM presympathetic neuron after CIH. In the presence of synaptic blockade, intrinsic spike discharge frequency (Bi, Bii), excitability properties (Ci, Cii, Ciii), and input resistance $\left[R_{\mathrm{i}}(\mathbf{D i}, \mathbf{D i i}, \mathbf{D i i i})\right]$ of nonmodulated RVLM presympathetic neurons were not affected by $\mathbf{C I H}$. Note that upon larger hyperpolarizing pulses in $\mathbf{D i}$ and $\mathbf{D i i}$, the membrane potential presented a shift toward more positive values as a time-dependent conductance was slowly turned on $(*)$.

evoked currents was taken as $I_{\mathrm{NaP}}$. Hyperpolarization-activated inward currents $\left(I_{\mathrm{h}}\right)$ were activated, in the presence of TTX, using a series of hyperpolarizing voltage pulses (from $-60 \mathrm{mV}$ to $-130 \mathrm{mV}$, in $10 \mathrm{mV}$ increments), from a $-70 \mathrm{mV}$ conditioning pulse. The ZD7288- (a selective blocker of $I_{\mathrm{h}}$ current) sensitive (40 $\mu \mathrm{M}$; Sigma-Aldrich) component of the hyperpolarizing-evoked currents represents the $I_{\mathrm{h}}$. T-type calcium currents were activated, in the presence of TTX, using a series of depolarizing command pulses (from -90 to $0 \mathrm{mV}$, in $10 \mathrm{mV}$ increments), from a hyperpolarizing conditioning pulse $(-90 \mathrm{mV})$. The recording of all ionic current were also performed in the presence of blockers of fast synaptic transmission in the perfusion solution [2.5-6.0 mM kynurenic acid, $20 \mu \mathrm{M}$ bicuculline (free-base), and $1 \mu \mathrm{m}$ strychnine; Sigma-Aldrich] and all signals were lowpass filtered at $1 \mathrm{kHz}$ and sampled at $5 \mathrm{kHz}$.

In current clamp, all data were low-pass filtered at $5 \mathrm{kHz}$ and digitized at the rate of $20 \mathrm{kHz}$. The intrinsic electrophysiological properties of respiratory-modulated RVLM presympathetic neurons were also evaluated in the presence of blockers of fast synaptic transmission in the perfusion solution.

Data analyses. All analyses of nerve recordings were performed off-line in rectified and smoothed $(50 \mathrm{~ms})$ signals using Spike 2 software with custom-written scripts. The respiratory modulation of sympathetic activity was analyzed using phrenic-triggered averages of tSN (generated from 1-2 min epochs of the recordings), which were divided into three parts: inspiration (coincident with inspiratory PN discharge), postinspiration (post-I; first half of expiratory phase), and late-expiration (late-E; second half of expiratory phase). The percentage of $\mathrm{tSN}$ activity in each phase was assessed by the measurement of the area under the curve and normalized by the total area, i.e., sum of areas obtained in inspiratory, post-I and late-E.

All analyses of neuronal recordings were performed using Clampfit 10 (Molecular Devices), GraphPad 5, and a custom script written in Spike 2 software. The peak conductance for each voltage $\left(G_{\mathrm{v}}\right)$ of the IA was calculated as $G_{\mathrm{v}}=I_{\text {peak }} /\left(V_{\mathrm{m}}-E_{\mathrm{K}}\right)$, where $I_{\text {peak }}$ is peak current, $V_{\mathrm{m}}$ membrane voltage, and $E_{\mathrm{K}}$ is the potassium equilibrium potential calculated from the Nernst equation (Hille, 2001). The relationship between normalized conductance and membrane potential $\left(V_{\mathrm{m}}\right)$ was fitted by a Boltzmann function of the form: $G=1 /\{1+\exp$ $\left.\left[\left(V_{\mathrm{h}}-V_{\mathrm{m}}\right) / V_{\mathrm{c}}\right]\right\}$, where $G$ is the relative membrane conductance, $V_{\mathrm{h}}$ is the voltage at halfmaximal conductance, and $V_{c}$ is the slope factor. Voltage-dependent inactivation of the IA was fitted with an equation of the form: $I / I_{\max }=1 /\left\{1+\exp \left[\left(V_{\mathrm{m}}-V_{\mathrm{h}}\right) / V_{\mathrm{c}}\right]\right\}$, where $I_{\max }$ is the maximal current recorded. Currentvoltage relationship of $I_{\mathrm{h}}$ was determined from steady-state currents. The voltage dependence of $I_{\mathrm{h}}$ activation was obtained from tail currents measured at $-80 \mathrm{mV}$ following a series of hyperpolarizing steps; those data were normalized and fitted with also an equation of the form: $I / I_{\max }=1 /\left\{1+\exp \left[\left(V_{\mathrm{m}}-V_{\mathrm{h}}\right) / V_{\mathrm{c}}\right]\right\}$. Current-voltage relationship of T-type calcium currents was determined from the peak currents after the capacitive transient.

Current-clamp recordings were analyzed off-line to measure: (1) resting membrane potential (RMP), (2) input resistance, (3) repetitive discharge characteristic of the neuron (frequency and interspike intervals of action potentials; the last was measured as the time difference between the peaks of the action potentials in response to $100 \mathrm{pA}$ of positive current injection), (4) duration of delayed excitation, and (5) amplitude of the after hyperpolarization potential (AHP). The input resistance was determined via linear regression applied to the linear portion of the voltage-current $(V-I)$ relationship. Considering that the RVLM presympathetic neurons always presented spontaneous spiking, it was difficult to clearly determine a stable membrane potential that could unequivocally be defined as the resting potential. To address this issue, we constructed an all-points histogram of $1 \mathrm{~min}$ of membrane potential value recorded in each experimental condition, and the resting membrane potential value was considered to be the value at which the cells spent most of the time, i.e., the peak of the distribution (da Silva et al., 2013). A liquid junction potential of 15 or $2 \mathrm{mV}$ (T-type calcium current) were corrected off-line.

Immunofluorescence. All preparations used for immunofluorescence were perfused transcardially first with PBS $(0.1 \mathrm{M})$ and then with $4 \%$ paraformaldehyde (PFA) and brains removed and postfixed in $4 \%$ PFA for $2-5 \mathrm{~d}$. Transverse sections ( $50 \mu \mathrm{m}$ thick) were cut through the RVLM with a vibrating microtome (Leica) and collected into a cryoprotectant solution and stored at $-20^{\circ} \mathrm{C}$ before further processing. The immuno- 
fluorescence was performed with free-floating sections. Sections were blocked and permeabilized in PBS containing 10\% normal horse serum and $0.5 \%$ Triton $\mathrm{X}-100$ for $1 \mathrm{~h}$ at room temperature. After three PBS washes, the slices were incubated in primary antibody mouse anti-tyrosine hydroxylase (TH; Millipore, $1: 1000$ ) for $24 \mathrm{~h}$ at $4^{\circ} \mathrm{C}$. After three PBS washes, the sections were incubated in secondary antibodies Alexa 488-conjugated streptavidin (1: 1000; Invitrogen) and Alexa 647-conjugated donkey anti-mouse (1:500; Jackson Laboratories) for $1 \mathrm{~h}$ at room temperature. Slices were washed three times in PBS and mounted in Fluoromount (Sigma-Aldrich). Images were collected on a Leica TCS SP5 confocal microscope equipped with 488 and $633 \mathrm{~nm}$ laser lines and tunable emission wavelength detection. For each preparation, biocytin-positive neurons were identified and confocal $z$ stacks were collected sequentially for the other channel to detect the TH-positive neurons and verify the colocalization.

Single-cell $q R T-P C R$. The cytoplasm of the neuron was pulled into a patch pipette with a slight negative pressure. We only applied negative pressure to pull the cytoplasm into a patch pipette in neurons presenting gigaseals and access resistance up to $20 \mathrm{M} \Omega$ at the end of whole-cell patchclamp records to give us a high success rate of identifying neuronal phenotypes using single-cell qRT-PCR. The cytoplasm was then placed into a microtube containing High Capacity cDNA Reverse Transcription Kit reagents (Life Technologies) and nuclease-free water for subsequent transcription in a thermocycler (Mastercycler Gradient-Eppendorf). A preamplification of the cDNA was performed using the TaqMan PreAmp Master Mix Kit (Life Technologies) with the following probes: Rn00562500_m1 (TH), Rn00584780_m1 (VGLUT ${ }_{2}$ ) and NM_031144.2 ( $\beta$-Actin; reference gene). The preamplification protocol consisted of a hold temperature at $95^{\circ} \mathrm{C}$ during $10 \mathrm{~min}$ and $14 \mathrm{cycles}$ of $95^{\circ} \mathrm{C}$ and $60^{\circ} \mathrm{C}$ during $15 \mathrm{~s}$ and $14 \mathrm{~min}$, respectively. The reactions for the single-cell qRT-PCR were performed in singleplex and triplicate (StepOnePlus System, Applied Biosystems) using the same probes described above and the TaqMan Universal PCR Master Mix kit (Life Technologies) according to the manufacture's recommendations.

Statistical analyses. Results are expressed as mean \pm SEM and compared using Student's unpaired $t$ test or one-way ANOVA, in accordance with the requirements of each experimental protocol. Differences were considered significant when $p<0.05$.

\section{Results}

Cardiovascular and respiratory recordings in awake rats and in in situ preparations

In a specific group of control and $\mathrm{CIH}$ rats we recorded arterial pressure, Abd, and DIA electromyogram in conscious, freely moving condition before identifying and characterizing the respiratory-modulated RVLM presympathetic neurons in in situ preparations. We observed that $\mathrm{CIH}$ produced a significant increase in the arterial pressure $(105 \pm 2$ vs $86 \pm 1 \mathrm{mmHg} ; p<$ $0.0001 ; n=39)$ and in the Abd activity during the late-E phase $(n=29$; Fig. $1 A i, A i i)$. These animals, in in situ preparations, also presented late-E activity in the $\mathrm{AbN}$ and an increase in the tSN
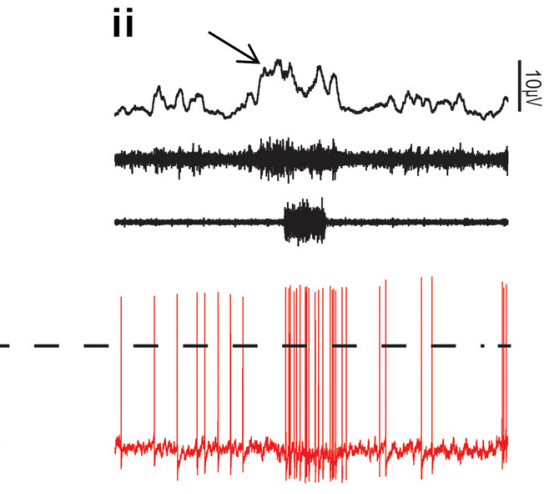

ii

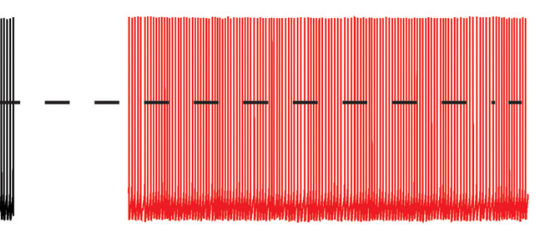

ii
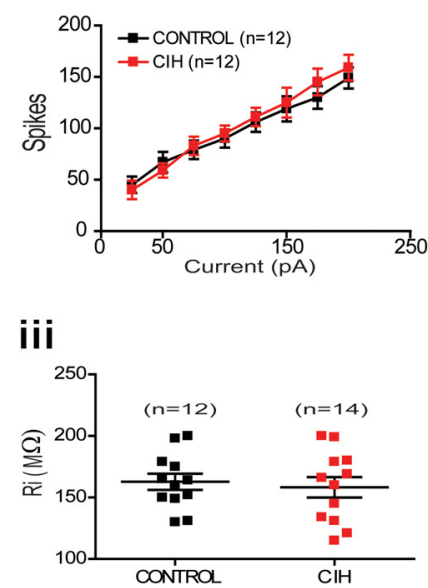

Figure 6. Spike discharge frequency and intrinsic electrophysiological properties of inspiratory-modulated RVLM presympathetic neurons from control and $\mathrm{CIH}$ rats. Raw and integrated $\left(\int\right)$ records of PN, $\mathrm{TSN}$, and inspiratory-modulated RVLM presympathe spike discharge frequency of inspiratory-modulated RVLM presympathetic neuron after CIH. In the presence of synaptic blockade, intrinsic spike discharge frequency (Bi, Bii), excitability properties (Ci, Cii, Ciii), and input resistance $\left[R_{\mathrm{i}}(\mathbf{D i}, \mathbf{D i i}, \mathbf{D i i i})\right]$ of inspiratory-modulated RVLM presympathetic neurons were not affected by $\mathrm{CIH}$.

activity during the same phase of respiratory cycle ( $55 \pm 2$ vs $33 \pm$ $5 \% ; n=39 ; p<0.0001$; Fig. $1 B i, B i i)$. After the characterization of the effects of $\mathrm{CIH}$ in the respiratory-sympathetic coupling of awake rats and in situ preparations, we used these rats $(n=39)$ and others $(n=93)$ to identify and characterize the different respiratory-modulated presympathetic neurons in the RVLM and their contribution to the respiratory-related increase in the sympathetic activity observed after $\mathrm{CIH}$.

\section{Identification of nonmodulated and respiratory-modulated RVLM presympathetic neurons in in situ preparations}

We were able to perform intracellular recordings of 132 presympathetic neurons in the RVLM region, which responded with a hyperpolarization and a transient inhibition of the spike discharge frequency in response to stimulation of the ADN (Fig. $2 A i)$. These neurons send projections to the spinal cord [antidromic latencies ranged from 2.2 to $10 \mathrm{~ms}$ (average $5.2 \pm 0.7$ 

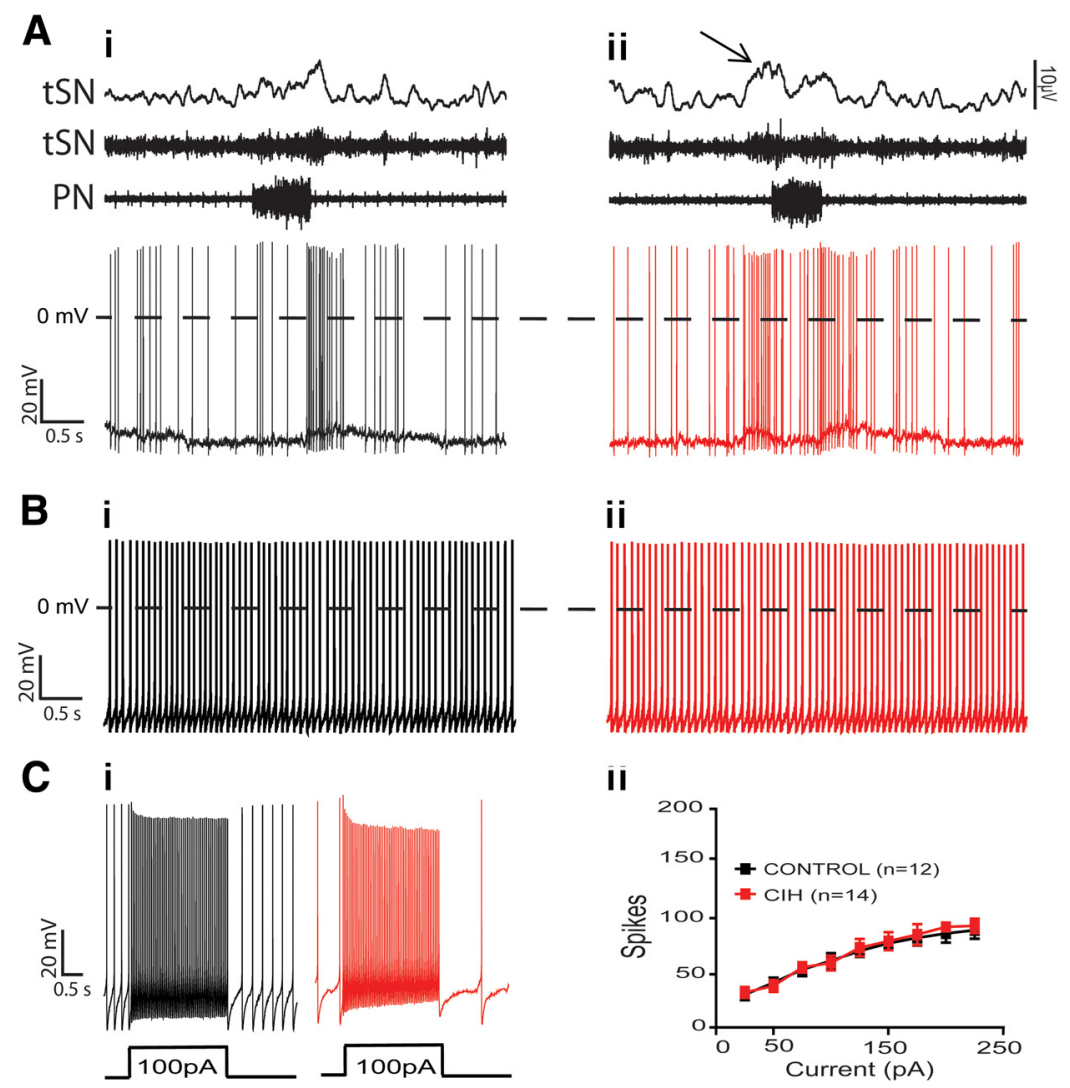

ii

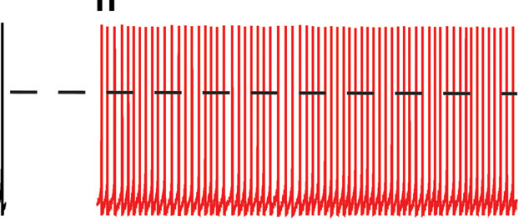

II
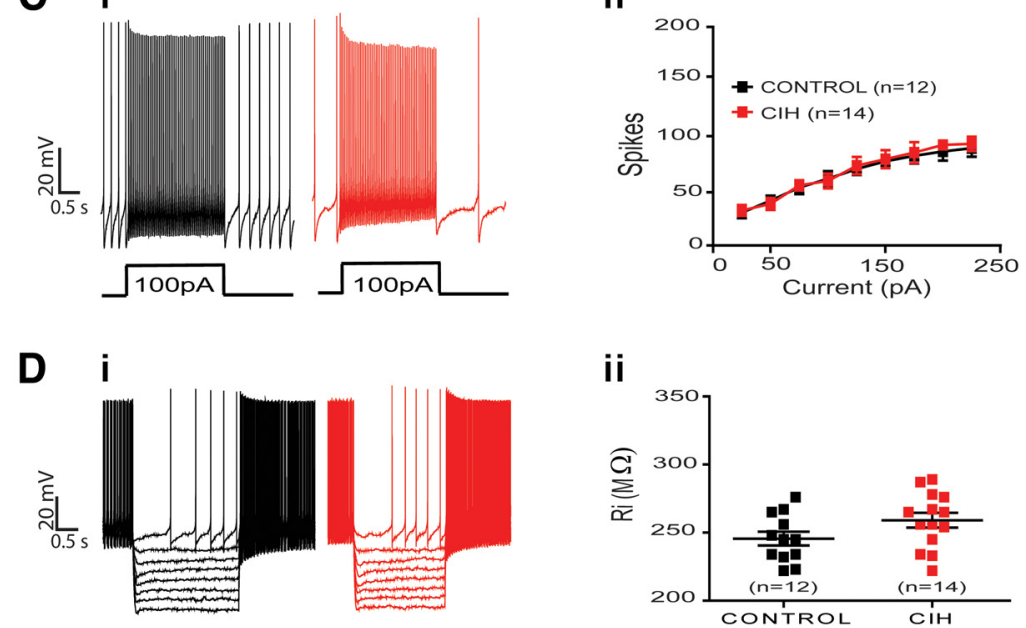

ii

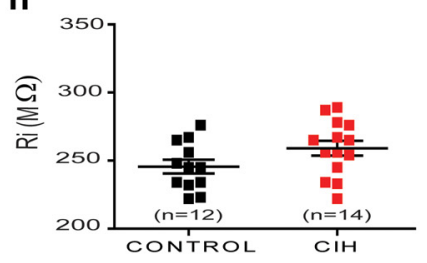

Figure 7. Spike discharge frequency and intrinsic electrophysiological properties of postinspiratory-modulated RVLM presympathetic neurons from control and CIH rats. Raw and integrated $\left(\int\right)$ records of PN, $\mathrm{SN}$, and postinspiratory-modulated RVLM presympathetic neurons activities from control (Ai) and $\mathrm{CIH}$ (Aii) rats. Note the presence of late-expiration (late-E; $\uparrow$ ) in $\mathrm{SSN}$ and an increase in the spike discharge frequency of presympathetic neuron in the same phase of respiratory cycle after $\mathrm{CIH}$. In the presence of synaptic blockade, intrinsic spike discharge frequency ( $\boldsymbol{B i}, \mathbf{B i i})$, excitability properties (Ci, Cii, Ciii), and input resistance $\left[R_{\mathrm{i}}(\mathrm{Di}, \mathrm{Dii}, \mathrm{Diii})\right]$ of postinspiratory-modulated RVLM presympathetic neurons were not affected by $\mathrm{ClH}$.

$\mathrm{ms})$ ] and had axonal conduction velocity that ranged from 1 to $4.5 \mathrm{~m} \cdot \mathrm{s}^{-1}\left[\left(\right.\right.$ average $\left.2.5 \pm 0.3 \mathrm{~m} \cdot \mathrm{s}^{-1}\right) ; n=132$; Figure 2 Aii $]$. The baroreceptor inhibition (latency: $27 \pm 1.6 \mathrm{~ms}$; amplitude: $5 \pm 0.9$ $\mathrm{mV} ; n=132$ ) suggests a chloride conductance, as demonstrated by reversals in the polarity of these potentials in response to a continuous application of negative current (Fig. 2Bi,Bii). A prominent feature of respiratory-modulated RVLM presympathetic neurons recorded in in situ preparations, an experimental condition in which the sympathetic and respiratory networks are preserved, was a high level of synaptic "noise." During baseline conditions, individual action potentials were usually interspersed by transient increase or decrease in their frequency discharge in the different phases of the respiratory cycle. When the firing was eliminated by a small continuous hyperpolarizing current, it was possible to observe the presence of spontaneous excitatory postsynaptic potentials (sEPSPs) and synaptic inhibition in the different phases of the respiratory cycle (Fig. 2Ci,Cii,Di,Dii). Considering these different synaptic inputs, we were able to clearly classify four groups of respiratorymodulated RVLM presympathetic neurons, in accordance with the firing pattern of each neuron in the different phases of the respiratory cycle: (1) neurons with a very regular pattern of action potential discharge; (2) neurons discharging action potentials in an irregular pattern with an inspiratory modulation; (3) neurons discharging action potentials in an irregular pattern with a pos-I modulation; and (4) neurons discharging action potentials in a regular pattern with an inspiratory inhibition.

To further investigate the respiratoryand nonrespiratory-related rhythmic activity of RVLM presympathetic neurons, we analyzed whether synaptic inputs, intrinsic electrophysiological properties, ionic currents, or the relation to $\mathrm{C} 1$ group of neurons were different in these four groups of RVLM presympathetic neurons. Considering that the exposure to $\mathrm{CIH}$ enhanced the central coupling between respiratory and sympathetic activities (Fig. 1Ai,Aii,Bi,Bii), the effects of a metabolic challenge produced by $\mathrm{CIH}$ on respiratory synaptic inputs and intrinsic electrophysiological properties of these neurons were also evaluated.

\section{Group I (nonmodulated)}

Catecholaminergic neurons belonging to the spinally projecting $\mathrm{C} 1$ group were identified using the single-cell qRT-PCR technique and immunofluorescence, while glutamatergic neurons were identified using single-cell qRT-PCR. All tested nonmodulated RVLM presympathetic neurons were positive TH-ir cells using immunofluorescence (control: 5 neurons; CIH: 5 neurons; Fig. 3Ai,Aii) and all tested neurons (control: 4 neurons) using single cell qRT-PCR for the presence of $\mathrm{VGLUT}_{2}$ also were positive (Fig. 3Aiii). During control condition, reduced spike discharge frequency with a small continuous hyperpolarizing current revealed few sEPSPs without relation to any specific phase of the respiratory cycle (Fig. 2Ci). After synaptic blockade, this group of neurons showed a resting membrane potential of $-53 \pm 2.2 \mathrm{mV}$, intrinsic spike discharge frequency of $6 \pm 1.1 \mathrm{~Hz}$, and an input resistance of $335 \pm 1.1 \mathrm{M} \Omega$ $(n=9$; Table 1$)$. The average number of actions potentials in response to $100 \mathrm{pA}$ of positive current was $46 \pm 6$ spikes (Table 1 ). A small decrease in the instantaneous spike discharge frequency and increase in the interspike interval in response to positive current injection were also observed (Fig. 4Ai,Aii). During larger negative current steps, an initial hyperpolarization followed by a shift of the membrane potential toward more positive voltages (sag) was also seen, suggesting the presence of a hyperpolarization-activated inward conductance (Fig. 5Di).

Nonmodulated RVLM presympathetic neurons from $\mathrm{CIH}$ hypertensive rats, with increased sympathetic activity during the late-E phase, presented no significant changes in the spike discharge 
frequency $(3.2 \pm 0.9$ vs $3 \pm 1 \mathrm{~Hz} ; n=19$; Fig. 5Ai,Aii) or any change in the intrinsic electrophysiological properties, such as resting membrane potential, intrinsic spike discharge frequency (Fig. 5Bi,Bii), number of spikes in response to positive current injection (Fig. 5Ci,Cii,Ciii), or input resistance (Fig. 5Di,Dii,Diii) when compared with nonmodulated RVLM presympathetic neurons from control rats $(n=19$; Table 1$)$. These data suggest that this group of $\mathrm{TH}-$ positive RVLM presympathetic neurons is not involved in the increased sympathetic activity observed after $\mathrm{CIH}$.

\section{Group II (inspiratory-modulated)}

All tested RVLM presympathetic neurons with inspiratory modulation were positive $\mathrm{TH}$-ir cells using immunofluorescence (control: 8 neurons; CIH: 8 neurons; Fig. $3 \mathrm{Bi}, \mathrm{Bii}$ ) and all tested neurons (control: 4 neurons) also expressed VGLUT 2 (Fig. 3Biii), as shown by single-cell qRT-PCR experiments. Reducing spike discharge frequency with a small continuous hyperpolarizing current revealed sEPSPs clearly correlated with the inspiratory phase (Fig. 2Cii), which may be responsible for the observed increase in their spike discharge frequency during inspiration. After synaptic blockade, this group of RVLM presympathetic neurons had a resting membrane potential of $-51 \pm 2.3 \mathrm{mV}$, intrinsic spike discharge frequency of $22 \pm 3 \mathrm{~Hz}$, and an input resistance of $162 \pm 6.5 \mathrm{M} \Omega(n=12$; Table 1$)$. The average number of actions potentials in response to $100 \mathrm{pA}$ of positive current was $90 \pm 8.7$ spikes. A sustained profile in the instantaneous spike discharge frequency and interspike interval responses to positive current injection (Fig. $4 \mathrm{Bi}$, Bii) were also observed.

Similar to nonmodulated RVLM presympathetic neurons, positive $\mathrm{TH}$-ir inspiratory-modulated neurons seem not to be involved in the increased sympathetic activity observed after $\mathrm{CIH}$ because the spike discharge frequency $(5 \pm 1.3$ vs $4 \pm$ $1.9 \mathrm{~Hz} ; n=24$; Fig. 6 Ai,Aii), resting membrane potential, intrinsic spike discharge frequency (Fig. 6Bi,Bii), number of spikes in response to positive current injection (Fig. 6Ci,Cii,Ciii), and input resistance (Fig. 6Di,Dii,Diii) were not significantly different from control rats $(n=24$; Table 1$)$.

\section{Group III (postinspiratory modulated)}

All tested RVLM presympathetic neurons with post-I modulation were negative TH-ir cells using immunofluorescence (control: 9 neurons; CIH: 7 neurons; Fig. 3Cii) and all tested neurons (control: 3 neurons) also expressed VGLUT 2 (Fig. 3Ciii), as shown by single cell qRT-PCR. Reducing their spike discharge frequency with a small continuous hyperpolarizing current revealed sEPSPs during the post-I phase (Fig. 2Di), which may be responsible for the increase in were event triggered.
$\mathbf{A}_{\mathbf{i}}$
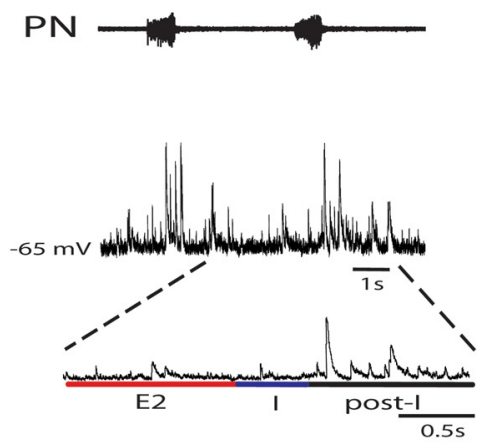

iii

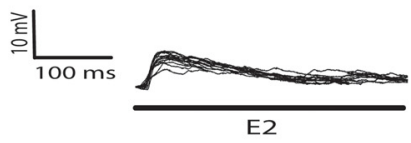

B i
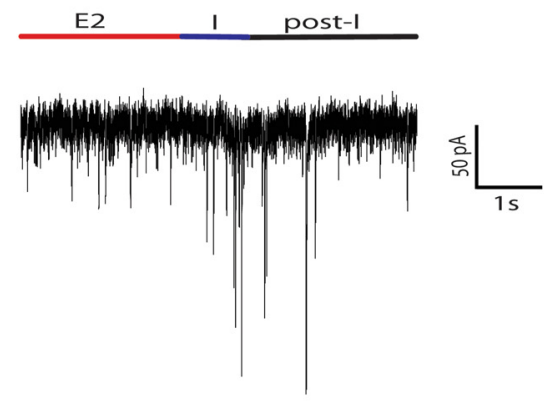

iii
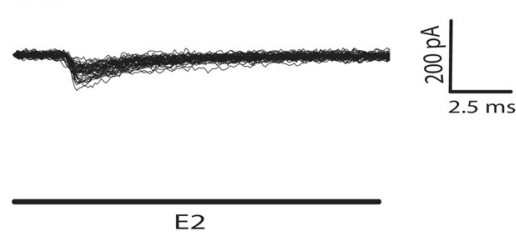

ii

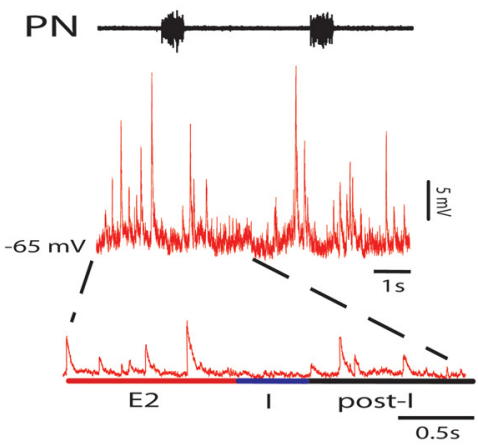

iv

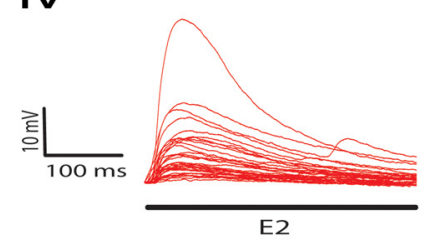

ii

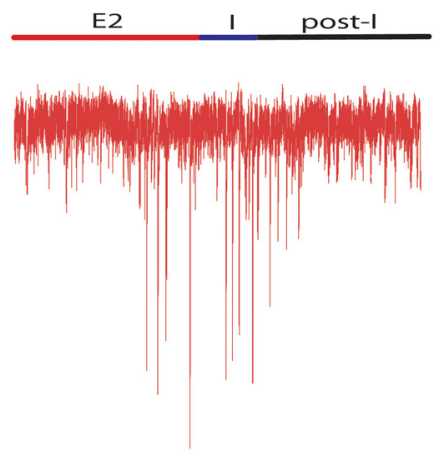

iv

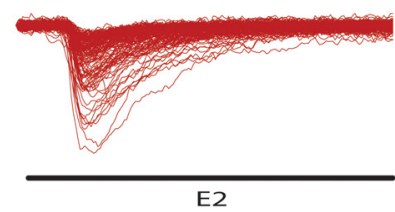

Figure 8. Effects of CIH on the synaptic inputs to the postinspiratory-modulated RVLM presympathetic neurons. SEPSPS, measured by hyperpolarizing the neurons, during different phases of respiration of postinspiratory-modulated RVLM presympathetic neurons from control (Ai) and $\mathrm{CIH}$ (Aii) rats. Note that $\mathrm{CIH}$ produced an increase in the frequency and amplitude of sEPSPs only during late-E (Aiii, Aiv). sEPSCS, measured at $-70 \mathrm{mV}$, during different phases of respiration of the same postinspiratorymodulated RVLM presympathetic neurons from control (Bi) and CIH (Bii) rats shown in $A$. Note that $\mathrm{CIH}$ also produced an increase in the frequency and amplitude of sEPSCs only during late-E (Biii, Biv). The superimposed sEPSPs (Aiii, Aiv) and sEPSCS (Biii, Biv)

their spike discharge frequency observed during post-I phase. Under conditions of synaptic blockade, their resting membrane potential was $-52 \pm 3.2 \mathrm{mV}$, intrinsic spike discharge frequency was $13 \pm 2$ $\mathrm{Hz}$, and input resistance was $245 \pm 5 \mathrm{M} \Omega(n=12$; Table 1$)$. The average number of actions potentials in response to $100 \mathrm{pA}$ of positive current was $61 \pm 7$ spikes (Table 1). A temporal increase in the instantaneous spike discharge frequency and decrease in the interspike interval responses to positive current injection were observed (Fig. 4Ci,Cii).

RVLM presympathetic neurons from hypertensive $\mathrm{CIH}$ rats, with post-I modulation, showed a significant increase in the spike 
A i
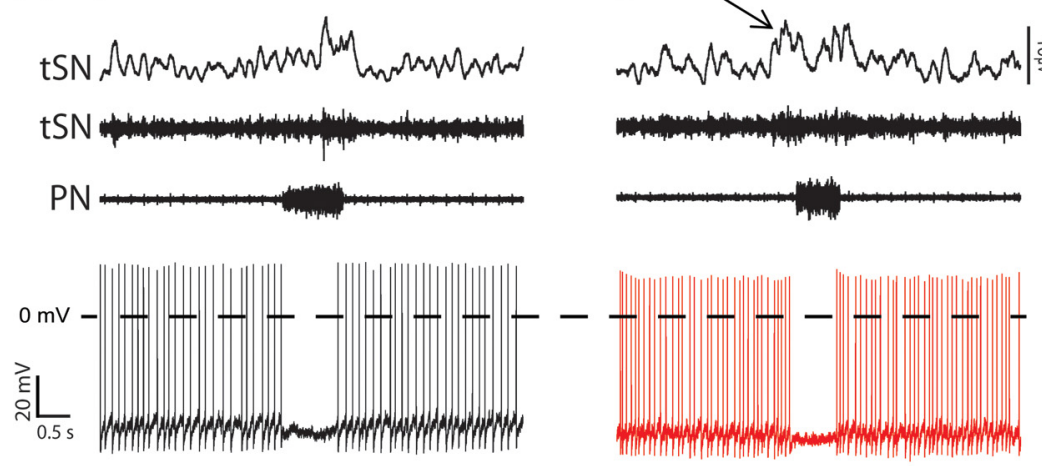

B i

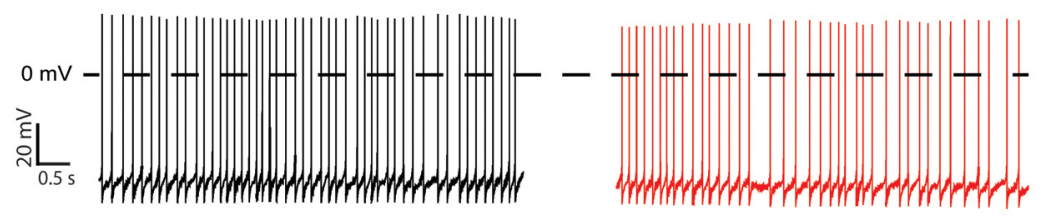

C i

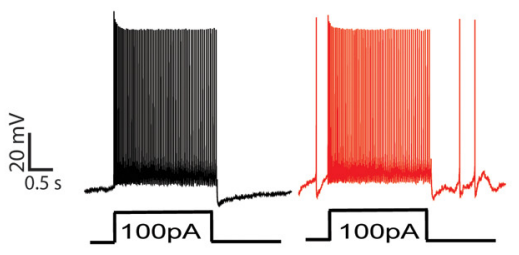

D i

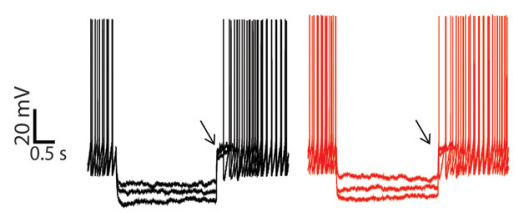

ii

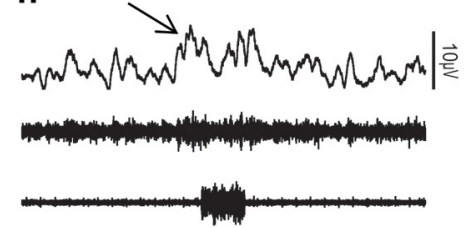

iii

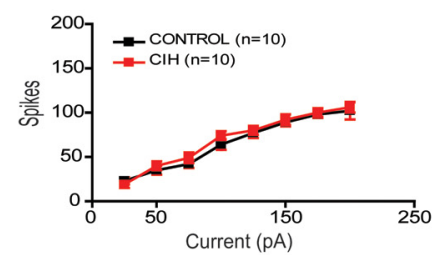

iii

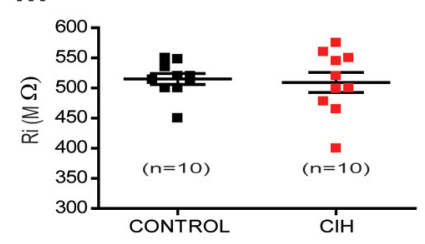

Figure 9. Spike discharge frequency and intrinsic electrophysiological properties of inspiratory-inhibited RVLM presympathetic neurons from control and $\mathrm{CIH}$ rats. Raw and integrated $\left(\int\right)$ records of PN, TSN, and inspiratory-inhibited RVLM presympathetic neurons activities from control $(\boldsymbol{A} \boldsymbol{i})$ and $\mathrm{CIH}(\boldsymbol{A i i})$ rats. Note the presence of late-expiration (late-E; $\uparrow)$ in $\mathrm{tSN}$ and no changes in the spike discharge frequency of inspiratory-inhibited RVLM presympathetic neuron after CIH. In the presence of synaptic blockade, intrinsic spike discharge frequency (Bi, Bii), excitability properties (Ci, Cii, Ciii), and input resistance $\left[R_{\mathrm{i}}(\mathbf{D i}, \mathbf{D i i}, \mathbf{D i i i})\right]$ of inspiratory-inhibited RVLM presympathetic neurons were not affected by $\mathrm{CIH}$. Note that after large hyperpolarizing current injection in Di and Dii, the inspiratory-inhibited RVLM presympathetic neurons expressed a delay in the rate of depolarizing and in the generation of action potentials ( $\uparrow$ ).

discharge frequency at the late-E phase $(35 \pm 3$ vs $4 \pm 1 \mathrm{~Hz} ; p<$ $0.0001 ; n=26$; Fig. 7Ai,Aii), which is well correlated with late-E $\mathrm{tSN}$ activity. Regarding the intrinsic electrophysiological properties, the data show that the spike discharge frequency (Fig. $7 \mathrm{Bi}-$ Bii), number of spikes in response to positive current injection (Fig. 7Ci,Cii,Ciii), and input resistance (Fig. 7Di,Dii,Diii) of RVLM presympathetic neurons, showing post-I modulation, were not affected by $\mathrm{CIH}(n=26$; Table 1$)$. This set of data indicates that increased sympathetic activity in in situ preparations of $\mathrm{CIH}$ rats is not due to changes in the intrinsic electrophysiological properties of the postinspiratory-modulated RVLM presympathetic neurons, but rather dependent on inputs from other groups of neurons, which are also part of the intact network. Therefore, on the next step, we evaluated the excitatory synaptic inputs to these neurons, by recording both spontaneous excitatory postsynaptic currents (sEPSCs) and sEPSPs, during

different phases of the respiratory cycle. Using this approach, we analyzed the possible source of the increased spike discharge frequency of this population of RVLM presympathetic neurons during the late-E phase. The results show that $\mathrm{CIH}$ increased the frequency of sEPSPs $(12 \pm 2.4$ vs $2.2 \pm 0.9 \mathrm{~Hz} ; p=0.001 ; n=$ 26; Fig. $8 A i-A i v)$ and sEPSCs $(14 \pm 2$ vs $2 \pm 0.5 \mathrm{~Hz} ; p<0.0001 ; n=26$; Fig. $8 B i-$ Biv) as well as their amplitudes [(sEPSPs: $19 \pm 3$ vs $9 \pm 2 \mathrm{mV} ; p=0.01 ; n=26$; Fig. $8 A i-A i v)$ (sEPSCs: $155 \pm 3$ vs $25 \pm 4 \mathrm{pA}$; $p<0.0001 ; n=26$; Fig. 8 Bi-Biv) ] only in the late-E phase. These findings indicate that the excitatory inputs, probably from expiratory neurons, drive the increased RVLM presympathetic neurons activities and, as a consequence, induce the increased sympathetic activity observed in $\mathrm{CIH}$ rats.

Group IV (inspiratory-inhibited)

All tested RVLM presympathetic neurons with inspiratory inhibition were negative $\mathrm{TH}$-ir cells using immunofluorescence (control: 7 neurons; CIH: 5 neurons; Fig. 3Di,Dii) and all tested neurons (control: 3 neurons) also expressed VGLUT $_{2}$ (Fig. 3Diii), as shown by single cell qRT-PCR. Reducing their spike discharge frequency with a small continuous hyperpolarizing current revealed a strong inhibition during the inspiratory phase (Fig. 2Dii). Under conditions of synaptic blockade, their resting membrane potential was $-54 \pm$ $3.4 \mathrm{mV}$, intrinsic spike discharge frequency was $8 \pm 1.9 \mathrm{~Hz}$, and input resistance was $515 \pm 9 \mathrm{M} \Omega(n=10$; Table 1$)$. The average number of actions potentials in response to $100 \mathrm{pA}$ of positive current was $64 \pm 6$ spikes (Table 1 ). In contrast to postinspiratory-modulated RVLM presympathetic neurons, it was possible to observe a spike frequency adaptation with an increase in the interspike interval in response to positive current injection in the inspiratory-inhibited RVLM presympathetic neurons (Fig. 4Di,Dii). After large hyperpolarizing current injection, the inspiratory-inhibited RVLM presympathetic neurons also expressed a delay in the rate of depolarization and in the generation of action potentials (Fig. 9Di). The current that underlies this delay excitation seems to be similar to a transient potassium current, activated upon depolarization from hyperpolarized potentials.

Despite the fact that inhibitory-modulated RVLM presympathetic neurons were negative TH-ir, similar to the postinspiratorymodulated neurons, they are not involved in the increased sympathetic activity after $\mathrm{CIH}$, because the spike discharge frequency ( $6 \pm 1.3$ vs $6.4 \pm 2.2 \mathrm{~Hz} ; n=20$; Fig. 9Ai,Aii), resting membrane potential, intrinsic spike discharge frequency (Fig. $9 \mathrm{Bi}$ Bii), number of spikes in response to positive current injection (Fig. 9Ci,Cii,Ciii), or input resistance (Fig. 9Di,Dii,Diii) were similar to 
the neurons from control rats $(n=20$; Table 1). The basic electrophysiological properties of the different populations of respiratorymodulated RVLM presympathetic neurons from control and $\mathrm{CIH}$ rats are summarized in the Table 1 and the differences between these properties in the four groups, when present, are indicated.

Hyperpolarization-activated inward conductance does not modulate the pacemaker activity of nonmodulated RVLM presympathetic neurons Only the group I of RVLM presympathetic neurons exhibits a hyperpolarizationactivated inward conductance (Fig. 5DiDii). Here, we examined the contribution of this inward conductance to pacemaker activity of group I of RVLM presympathetic neurons. Small injections of negative current $(-25 \mathrm{pA})$ cause a hyperpolarizing membrane response that is maintained throughout the duration of the current pulses (Fig. 5Di,Dii). In contrast, larger hyperpolarizing pulses produced a "sag" (Fig. $5 D i, D i i)$. This sag is consequence of the activation of a time-dependent inward conductance. Under voltage-clamp, hyperpolarizing voltage steps $(-70$ to $-130 \mathrm{mV})$, from a holding potential of $-70 \mathrm{mV}$, revealed a slowly activating inward current (Fig. 10Ai). This inward current reached a plateau after several hundred milliseconds and showed no inactivation in the time window in which it was recorded. Addition of ZD7288 $(40 \mu \mathrm{M})$, a selective blocker of $I_{\mathrm{h}}$, to the perfusion resulted in a significant reduction in this current (Fig. 10Aii). Off-line subtraction of the inward current before and after the perfusion with ZD7288 revealed the $I_{\mathrm{h}}$, which starts to be activated $\sim-70 \mathrm{mV}$ with peak at $-130 \mathrm{mV}(-335 \pm$ $11 \mathrm{pA} ; n=6$; Fig. 10Aiii,Bi), half-activation voltage of $-97.3 \pm 0.6 \mathrm{mV}$, and a slope factor of $-7.1 \pm 0.6 \mathrm{mV}$ (Fig. 10Bii). We examined the participation of this $I_{\mathrm{h}}$ in the pacemaker activity of RVLM presympathetic neurons by using ZD7288 in the perfusion. The effect of ZD7288 on the spike discharge frequency of nonmodulated $\mathrm{C} 1$ pacemaker neuron is illustrated in the Figure 10, $\mathrm{Ci}$ and $\mathrm{Cii}$. Selective blockade of $I_{\mathrm{h}}$ produced no changes in the pacemaker spike discharge frequency of group I of RVLM presympathetic neurons $(7 \pm 1.6$ vs $6 \pm 1.1 \mathrm{~Hz} ; n=9$; Fig. $10 \mathrm{Ci}$,Cii).

Properties of low-threshold spike and T-type calcium currents in the inspiratory- and postinspiratory-modulated RVLM presympathetic neurons

As shown in Figure 11Ai, a burst discharge was evoked at the end of a hyperpolarizing pulse, which was followed by a train of action potentials, only in the groups II and III of RVLM presympathetic neurons. In the presence of TTX, a prominent low-threshold spike (LTS) was displayed at the end of a hyperpolarizing pulse,

B

C i pathetic neuron.

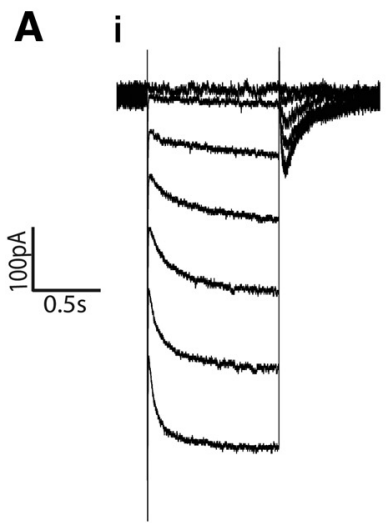

ii

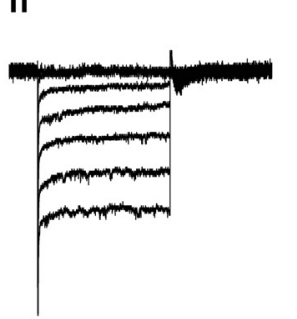

iii

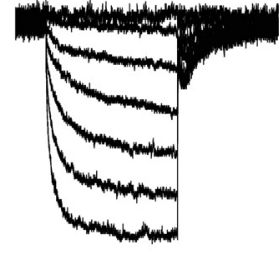

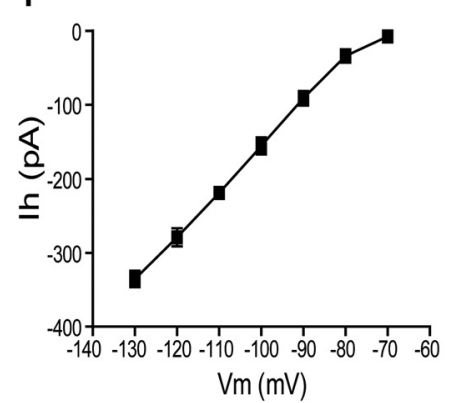

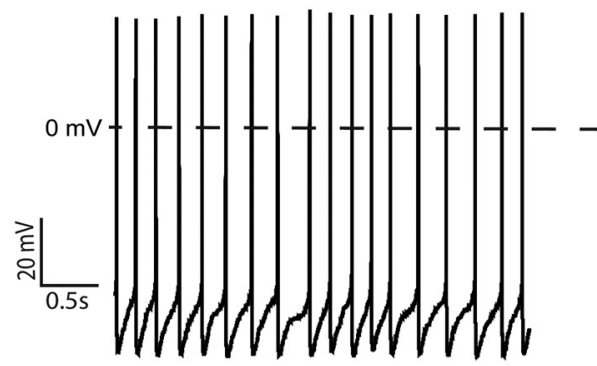

Figure 10. Bulbospinal nonmodulated pacemaker RVLM presympathetic neurons express hyperpolarization-activated inward current $\left(I_{\mathrm{h}}\right)$. Ai, Hyperpolarizing voltage steps ( $-10 \mathrm{mV}$ increments) from a holding potential of $-70 \mathrm{mV}$ evoked a timedependent inward current in the nonmodulated RVLM presympathetic neuron. Aii, The inward current is reduced by addition of $7288(40 \mu \mathrm{M})$, a selective blocker of the $I_{\mathrm{h}}$, to the perfusion solution. Aiii, Off-line subtraction of the traces presented in $\boldsymbol{A i}$ and ing the $I_{\mathrm{h}} \mathrm{ZD} 7288$-sensitive current. $\boldsymbol{B i}$, Current-voltage relationship of the steady-state portion of the averaged $I_{\mathrm{h}}$. $B$ ii, $I_{\mathrm{h}}$ activation curve (Boltzman fitted; see Materials and Methods) showing the voltage dependence of the inward current. $C_{i}$ Represtative tracing of the pacemaker activity of nonmodulated RVLM presympathetic before and after (Cii) perfusion with ZD7288. Addition of ZD7288 produced no changes in the pacemaker spike discharge frequency of nonmodulated RVLM presym-

which was blocked by perfusion of $50 \mu \mathrm{M} \mathrm{Ni}^{2+}$, a known T-type calcium channel blocker (Fig. 11Aii).

T-type calcium currents were activated using a series of depolarizing command pulses (from -90 to $0 \mathrm{mV}$, in $10 \mathrm{mV}$ increments). The peak amplitudes of the evoked currents were plotted as a function of the command potential (I/V plots) and the voltage-dependent activation of the evoked currents was assessed. A representative example of one RVLM presympathetic neuron from group III is shown in Figure 11Aiii. On average, the peak of activation of T-type calcium current in the groups II and III of RVLM presympathetic neurons was $-50 \mathrm{mV}$, and there was no difference in the T-type calcium currents between these groups of neurons (at $-50 \mathrm{mV}:-2.05 \pm 0.6 \mathrm{vs}-2.2 \pm 0.7 \mathrm{pA} / \mathrm{pF}$ from group II and group III, respectively; $n=10$; Fig. $11 \mathrm{Bi}$ ). We investigated a possible role of T-type calcium currents in the 
A<smiles>[In]I</smiles>

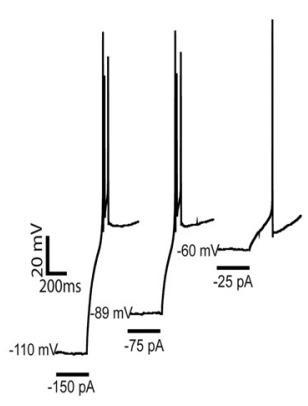

ii

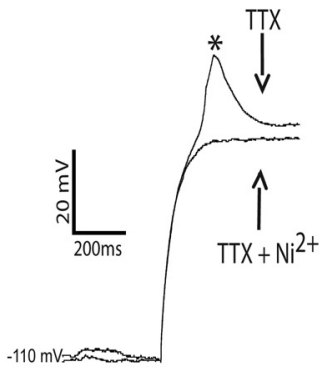

B i

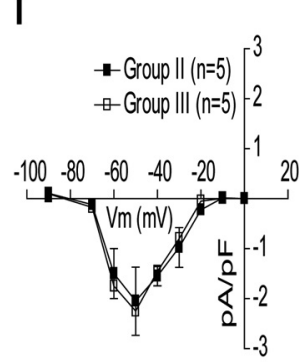

ii

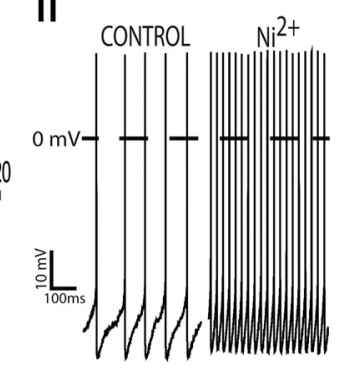

iii

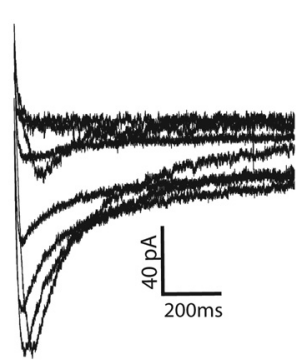

iii

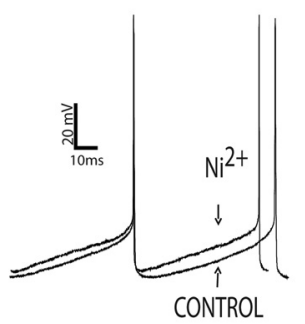

Figure 11. Electrophysiological properties of LTS and T-type calcium current in the bulbospinal inspiratory- and postinspiratory-modulated RVLM presympathetic neurons. Ai, Examples of electrophysiological recordings obtained from one representative postinspiratory-modulated RVLM presympathetic neuron showing the generation of a burst discharge at the end of a hyperpolarizing pulse ( 2 s, at different holding currents) followed by a train of action potentials. Aii, In the presence of TTX $(0.5$ $\mu \mathrm{M})$, the LTS appeared at the end of the hyperpolarizing pulses as a short-lasting depolarizing hump and it was entirely blocked by $50 \mu \mathrm{M} \mathrm{Ni}^{2+}$. Aiiii, T-type calcium current obtained from another postinspiratory modulated RVLM presympathetic neuron using a series of depolarizing command pulses (from -90 to $0 \mathrm{mV}$, in $10 \mathrm{mV}$ increments), from a hyperpolarizing conditioning pulse of $-90 \mathrm{mV}$. Bi, Average peak amplitudes of the evoked currents as a function of the command potential in the groups II and III of RVLM presympathetic neurons. Bii, In current-clamp mode, the pacemaker spike discharge frequency, of the same postinspiratory-modulated RVLM presympathetic neuron showed in $\boldsymbol{A i}$, increased after application of $\mathrm{Ni}^{2+}$. Biii, $\mathrm{Ni}^{2+}$ reduced the amplitude of after-hyperpolarization potential, causing a shorter duration of the interspike interval. Group II: inspiratorymodulated RVLM presympathetic neurons; Group III: postinspiratory-modulated RVLM presympathetic neurons.

pacemaker activity with $\mathrm{Ni}^{2+}$ in the perfusion in the groups II and III of RVLM presympathetic neurons. In the example of one RVLM presympathetic neuron from group III (Fig. 11Bii,Biii), $\mathrm{Ni}^{2+}$ did not block the pacemaker activity, but induced a depolarization [(group II: $-46 \pm 0.8$ vs $-51 \pm 2.3 \mathrm{mV} ; n=12 ; p<$ $0.05)$ (group III: $-45 \pm 0.5$ vs $-52 \pm 3.2 \mathrm{mV} ; n=12 ; p=0.04)$ ] and increased spike discharge frequency [(group II: $36 \pm 5.5$ vs $22 \pm 3 \mathrm{~Hz} ; n=12 ; p=0.03$ ) (group III: $25 \pm 3.5$ vs $13 \pm 2 \mathrm{~Hz}$; $n=12 ; p=0.007)]$.

\section{Role of voltage-activated outward conductance in the pacemaker activity of inspiratory-inhibited RVLM presympathetic neurons}

The transient A-type voltage-dependent IA, only expressed in the group IV of RVLM presympathetic neurons (Fig. 9Di,Dii), is characterized by a strong voltage dependence and rapid activation and inactivation kinetics, resulting in a transient outward current (Fig. 12Ai). Depolarizing steps of increasing amplitudes $(-80$ to $60 \mathrm{mV}$, in $10 \mathrm{mV}$ increments) were used to activate IA. The average IA peak current density at $60 \mathrm{mV}$ was $71 \pm 5.2 \mathrm{pA} / \mathrm{pF}$ ( $n=6$; Fig. 12Aii). Plots of conductance versus membrane potential show a half-activation voltage of $-39.1 \pm 1.6 \mathrm{mV}$, with a slope factor of $12 \pm 1.4 \mathrm{mV}$ (Fig. 12Bi). The voltage dependence of inactivation was then studied (Fig. 12Aiii). The average IA half-inactivation potential was $-68 \pm 0.6 \mathrm{mV}$ with a slope factor of $-11.7 \pm 0.6$ (Fig. 12Bi). When the voltage-dependent activation and inactivation curves of IA were plotted together, a small overlapping area between these two curves (i.e., "window current") at potentials between $-70 \mathrm{mV}$ to $-35 \mathrm{mV}$ was observed (Fig. 12Bi).

Since the IA was active in the voltage range traversed by pacemaker potentials ("window current"), we examined the modulatory effect of IA on the pacemaker activity of group IV of RVLM presympathetic neurons by using a blocker of this conductance, 4-aminopyridine (4-AP; 5 $\mathrm{mm}$; Sigma-Aldrich), in the perfusion solution. Application of 4-AP resulted in an increase in the pacemaker spike discharge frequency, from $8 \pm 1.9 \mathrm{~Hz}$ to $13 \pm 0.9 \mathrm{~Hz}$ $(n=10 ; p=0.03$; Fig. 12Bii,Biii).

\section{Persistent sodium current is essential for pacemaker activity of nonmodulated and respiratory- modulated RVLM presympathetic neurons}

To further address the pacemaker activity of respiratory-modulated RVLM presympathetic neurons, the presence of $I_{\mathrm{NaP}}$ was tested directly in the voltage-clamp mode. An example of one inspiratory-modulated RVLM presympathetic neuron is illustrated in Figure $13 A$. To isolate $I_{\mathrm{NaP}}$ and study its current-voltage relationship without concomitant activation of fast sodium currents, we used slow depolarizing voltage ramps $(30 \mathrm{mV} / \mathrm{s})$ from a holding potential of -85 to $15 \mathrm{mV}$. The activation of $I_{\mathrm{NaP}}$ was evident $\sim-55 \mathrm{mV}$ and reached its peak amplitude between -40 and $-35 \mathrm{mV}$. Application of riluzole $(10 \mu \mathrm{M})$ substantially reduced the inward deflection indicating that riluzole-sensitive sodium current underlies this conductance (Fig. 13A).

To test the hypothesis that $I_{\mathrm{NaP}}$ may be differentially expressed in the different groups of RVLM presympathetic neurons, we compared the amplitude of their riluzole-sensitive current. As illustrated in the Figure $13 B$, the peak current density of $I_{\mathrm{NaP}}$ was significantly different between some of the RVLM presympathetic neurons and all RVLM presympathetic pacemaker neurons expressed $I_{\mathrm{NaP}}$ [(group I: $0.5 \pm 0.06 \mathrm{pA} / \mathrm{pF} ; n=5$ ) (group II: $3.3 \pm 0.2 \mathrm{pA} / \mathrm{pF} ; n=5)$ (group III: $0.99 \pm 0.07 \mathrm{pA} / \mathrm{pF} ; n=6$ ) (group IV: $0.96 \pm 0.06 \mathrm{pA} / \mathrm{pF} ; n=5$ )]. The voltage-clamp data are consistent with the observed inhibition of pacemaker spike discharge frequency by blocking $I_{\mathrm{NaP}}$ with riluzole (Fig. 13C), by hyperpolarization to voltages higher than $-55 \mathrm{mV}$, and clearly implicate $I_{\mathrm{NaP}}$ as the main conductance underlying pacemaker potentials in the nonmodulated and respiratory-modulated RVLM presympathetic neurons after synaptic blockade.

\section{Discussion}

We are showing that bulbospinal respiratory-modulated RVLM presympathetic neurons constitute a heterogeneous neuronal population regarding their electrophysiological properties, synaptic inputs, and expression of ionic current, albeit all presympathetic neurons presented intrinsic pacemaker activity after 
synaptic isolation. This pacemaker activity of $\mathrm{Cl}$ and adjacent non-C1 respiratorymodulated presympathetic neurons, in in situ preparations, is due to an intrinsic cellular mechanism dependent on $I_{\mathrm{NaP}}$. We are also showing that the increase in the spike discharge frequency of the respiratorymodulated presympathetic neurons, in a condition of metabolic challenges in rats produced by $\mathrm{CIH}$, is restricted to a specific subpopulation of neurons (non-C1 postinspiratory-modulated), which presents an enhancement of the excitatory synaptic inputs from the respiratory network.

In the present study we identified three types of respiratory-modulated RVLM presympathetic neurons, as well as a fourth type showing no respiratory-related modulation. All these subpopulations of neurons correspond qualitatively to the patterns reported by other laboratories using in vivo anesthetized animals (McAllen, 1987; Haselton and Guyenet, 1989; Miyawaki et al., 1995). The firing pattern of group II of RVLM presympathetic neurons is quite similar to the pattern of activity recorded from cardiac, splanchnic, and adrenal sympathetic nerves (Numao et al., 1987). The discharge pattern of the group III of RVLM presympathetic neurons closely matched the pattern seen in the lumbar sympathetic nerve activity (Haselton and Guyenet, 1989) and in postganglionic neurons innervating the vasoconstrictor muscle (Häbler et al., 1993). Therefore, we are showing that the different patterns of the respiratory-modulated RVLM presympathetic neurons recorded are due to direct synaptic inputs from distinct respiratory neurons, and it may explain the regional differences in sympathetic nerve activity innervating different vascular beds (Numao et al., 1987).

Previous studies showed that the RVLM presympathetic $\mathrm{C} 1$ neurons are implicated in cardiovascular control (Allen and Guyenet, 1993; Lipski et al., 1995a). We used single-cell qRT-PCR and immunofluorescence to study the expression of $\mathrm{TH}$ and VGLUT $_{2}$ within functionally identified respiratory-modulated RVLM presympathetic neurons. Despite the fact that all respiratory-modulated RVLM presympathetic neurons investigated with qRT-PCR were glutamatergic neurons, we detected the TH mRNA only in the groups I and II of presympathetic neurons. The efficiency of our TH primer to detect mRNA at the single cell level is supported by our findings of TH protein expression only in RVLM neurons from groups I and II.

We documented that $\mathrm{C} 1$ respiratorymodulated RVLM presympathetic neurons send direct projections to sympathetic
A

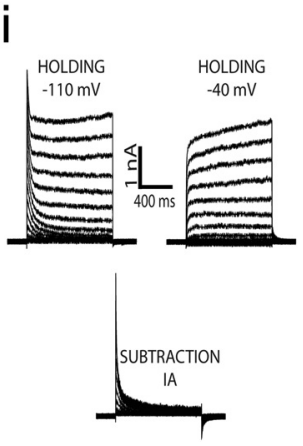

B

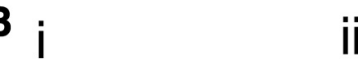

ii

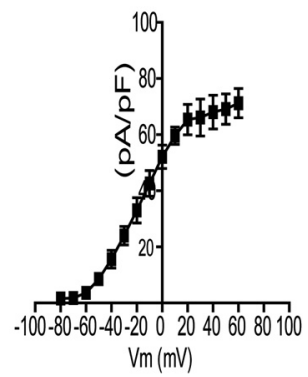

ii

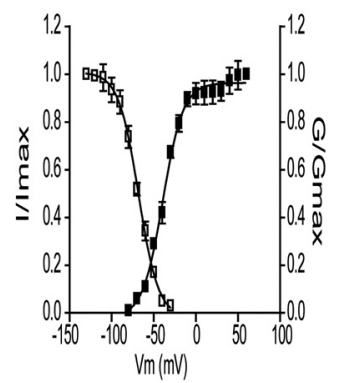

iii

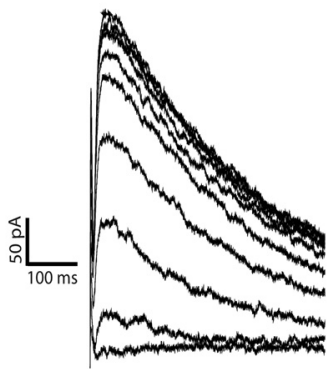

iii

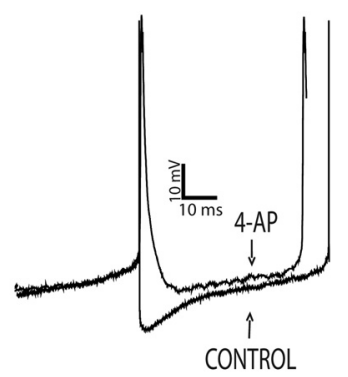

Figure 12. Modulatory effect of IA on the pacemaker frequency of bulbospinal inspiratory-inhibited RVLM presympathetic neurons. Ai, Transient IA current and a sustained outward current of a pacemaker nonmodulated RVLM presympathetic neuron elicited by depolarizing voltage steps (from -80 to $60 \mathrm{mV}$ ) with a holding voltage either of $-110 \mathrm{mV}$ or $-40 \mathrm{mV}$. With the off-line subtraction of the currents evoked with holding voltage of -110 and $-40 \mathrm{mV}$, the IA current was isolated. Aii, Average amplitude of IA current measured at the peak values of the subtracted current showed in Ai. Aiii, Voltage-dependent inactivation was measured as the decrease in IA during a step to $-30 \mathrm{mV}$ after $1 \mathrm{~s}$ of preholding potentials from -130 to $-30 \mathrm{mV}$. Bi, When the average normalized IA amplitude obtained with the voltage-dependent activation ( $\square$ ) and inactivation $(\square)$ protocols are plotted together (Boltzmann fitted — see Materials and Methods) as a function of the command potential, a region of overlap between $-70 \mathrm{mV}$ and $-35 \mathrm{mV}$ was observed. Bii, In current-clamp mode, the pacemaker spike discharge frequency of the inspiratory-inhibited RVLM presympathetic neuron increased after application of 4-AP (5 mm). Biii, Broadening of a pacemaker action potential and reduction of after-hyperpolarization potential in the presence of 4-AP was observed.
A

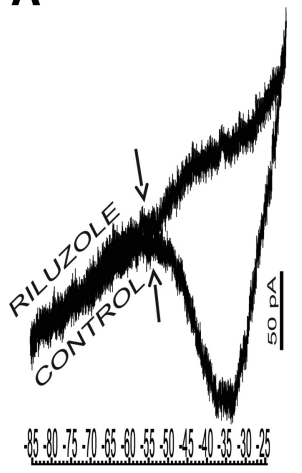

B

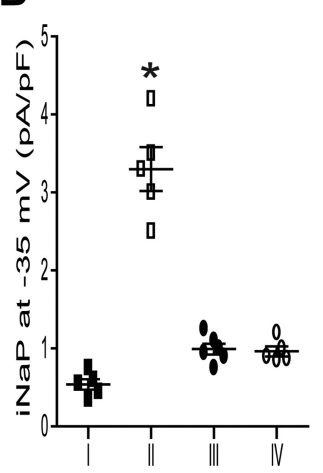

C

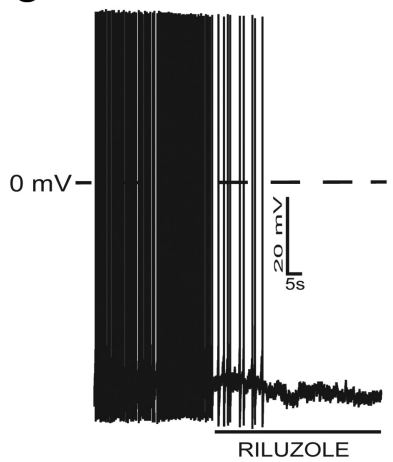

Figure 13. Persistent sodium current $\left(I_{\mathrm{NaP}}\right)$ underlies the pacemaker activity in bulbospinal nonmodulated and respiratorymodulated RVLM presympathetic neurons. $\boldsymbol{A}$, Representative current response of one inspiratory-modulated RVLM presympathetic neuron from control rats voltage-clamped to a slow depolarizing voltage ramp ( $30 \mathrm{mV} / \mathrm{s}$ ) applied from a holding potential of $-85 \mathrm{mV}$ to $-25 \mathrm{mV}$. A developing slow inward current was evident as a negative slope conductance on the current-voltage plot with activation voltage $(\uparrow) \sim-55 \mathrm{mV}$. Riluzole $(10 \mu \mathrm{m})$ completely suppressed the inward current. $\boldsymbol{B}$, Comparison of the riluzole-sensitive $I_{\mathrm{NaP}}$ at $-30 \mathrm{mV}$, expressed as peak current density, between all pacemaker RVLM presympathetic neurons. Note that the group II of RVLM presympathetic neurons presented a higher $I_{\mathrm{NaP}}$ current density in relation to other groups of neurons. $\boldsymbol{C}$, Representative voltage traces of the pacemaker activity of same inspiratory-modulated RVLM presympathetic neuron showed in $\boldsymbol{A}$. Riluzole blocked the spontaneous spike discharge frequency of the bulbospinal pacemaker inspiratory-modulated RVLM presympathetic neuron. Group I: nonmodulated RVLM presympathetic neurons; Group II: inspiratory-modulated RVLM presympathetic neurons; Group III: postinspiratory-modulated RVLM presympathetic neurons; Group IV: inspiratory-inhibited RVLM presympathetic neurons; ${ }^{*} p<0.05$ in relation to the groups I, III, and IV of RVLM presympathetic neurons. 
preganglionic neurons in the spinal cord, indicating that they are undoubtedly part of the neural substrate that regulates the cardiovascular system as showed before for cardiac-modulated neurons (Reis et al., 1989; Ruggiero et al., 1989; Allen and Guyenet, 1993). We also documented that $\mathrm{C} 1$ neurons are not the only group of respiratory-modulated presympathetic neurons that drive the sympathetic outflow. The increased sympathetic activity observed in in situ preparations of $\mathrm{CIH}$ rats was due to changes in the spike discharge frequency of non- $\mathrm{C} 1$ postinspiratory-modulated presympathetic neurons during the late-E phase, whose mechanisms are dependent on glutamatergic synaptic inputs from respiratory network. These results corroborate the hypothesis that elevations in sympathetic activity, in different models of hypertension, might involve exaggerated respiratory-sympathetic coupling (CzyzykKrzeska and Trzebski, 1990; Toney et al., 2010; Moraes et al., 2012a). The data of the present study provide a mechanistic insight to explain why $\mathrm{CIH}$ awake rats, which are also hypertensive, presented active expiration in the abdominal muscle in the same phase of increased spike discharge frequency of presympathetic neurons observed in in situ preparations.

We identified differences in some of the electrophysiological properties of respiratory-modulated RVLM presympathetic neurons, such as intrinsic excitability, which may be related to differences in ionic conductances operating at or close to the resting membrane potential, albeit all neurons presented pacemaker activity after synaptic blockade. However, before the synaptic blockade when these cells were receiving multiple synaptic inputs, the pattern of spike discharge frequency was probably determined by the balance of excitatory and inhibitory inputs, as also observed in in vivo anesthetized rats (Lipski et al., 1995b), in which experiments the synaptic blockade was not performed. Although these cells, as part of a complex network, are in charge of the generation of sympathetic activity, it does not imply that under this condition their spike discharge frequency is driven by their intrinsic pacemaker properties.

The ionic currents underlying the hyperpolarization activated inward conductance in the group I of presympathetic neurons resembles $I_{\mathrm{h}}$, a well characterized current in a variety of neurons in the CNS(McCormick and Pape, 1990; Sirois et al., 2002) and in heart pacemaker cells (Brown et al., 1984). The $I_{\mathrm{h}}$ can accelerate pacemaker frequency of presympathetic neurons by increasing the slope of the depolarizing phase of the membrane potential. However, this current is not essential for pacemaker activity of the group I of presympathetic neurons. This is indicated by the results showing that the $I_{\mathrm{h}}$ blockade by ZD7288 produced no effect on the pacemaker activity. In this case we suggest that the membrane potential of these neurons after synaptic blockade was more depolarized than the voltage necessary to activate the $I_{\mathrm{h}}$.

One of the most prominent intrinsic properties observed in the groups II and III of RVLM presympathetic was the presence of calcium-dependent LTS. The concept that the expression of the LTS in presympathetic neurons is mediated by the activation of T-type calcium current is supported by the voltage-dependent properties and sensitivity to micromolar concentrations of $\mathrm{Ni}^{2+}$ (Lee et al., 2008). Similarly, the involvement of T-type calcium current underlying the LTS has been shown previously in presympathetic neurons (Sun and Reis, 1994) and in other neuronal types (Luther and Tasker, 2000; Stern, 2001). The LTS has been demonstrated to play a major role in brain areas showing neuronal oscillations and burst firing (Llinás and Yarom, 1981). We suggest that in the groups II and III of presympathetic neurons, calcium influx is not the main conductance underlying pacemaker activity, but plays a minor role probably acting indirectly by inducing a calcium-activated potassium channel $\left[\left(\mathrm{BK}_{\mathrm{Ca}}\right)\right.$ (Pierrefiche et al., 1995)]. This conductance underlies AHP in neurons and appears to be a potent modulator of their spike discharge frequency, which can explain the increase in the spike discharge frequency and depolarization after the blockade of T-type calcium channels in the groups II and III of presympathetic neurons.

Depolarizing steps of sufficient amplitude activated a transient outward current in the group IV of RVLM presympathetic neurons. Along with studies by Kangrga and Loewy (1995) using brainstem slices, we observed that this current resembles IA, which is involved in the generation of delay excitation. In agreement with previous reports in other neuronal types (Belugin and Mifflin, 2005; Wang and Schreurs, 2006; Sonner and Stern, 2007), our data support the concept that a tonically active IA (i.e., "window" current) is present in group IV of presympathetic neurons. This window current was found to be active in a narrow, although physiologically relevant, range of membrane potential, and it may play a role in setting resting membrane potential in pacemaker presympathetic neurons.

The voltage dependence of the $I_{\mathrm{Nap}}$ recorded in respiratorymodulated RVLM presympathetic neurons resemble that described in other pacemaker neurons (Koizumi and Smith, 2008; Liu and Shipley, 2008). Our results suggest that $I_{\text {Nap }}$ drives the pacemaker activity of nonmodulated and respiratory-modulated RVLM presympathetic neurons because: (1) the $I_{\text {Nap }}$ is activated at voltages $\sim-55 \mathrm{mV}$ and reach its peak amplitude at $-35 \mathrm{mV}$. This is consistent with the observation that pacemaker spike discharge frequency is generated only when membrane potential is $\sim-55 \mathrm{mV}$; (2) the pacemaker activity is blocked by addition of riluzole, a selective blocker of $I_{\mathrm{NaP}}$, or by hyperpolarization. Studies by Kangrga and Loewy (1995) showed the presence of an inward sodium current in $\mathrm{Cl}$ bulbospinal neurons, and that this current was significantly larger in pacemaker than in nonpacemaker $\mathrm{C} 1$ neurons in brainstem slices. A similar current is present in locus ceruleus cells and may contribute to the pacemaker activity of these cells as well (Williams et al., 1991). However, this current is also present in other cell types (hippocampal neurons) that do not fire spontaneously (French et al., 1990). This may indicate that not only is $I_{\mathrm{NaP}}$ essential for expressing pacemaker activity of presympathetic neurons, but the expression of other currents, such as leak currents that by interacting with the $I_{\mathrm{NaP}}$ may affect the excitability of these neurons and be a functional set of subthreshold conductances as a potential targets for neuromodulatory control of sympathetic outflow.

In conclusion, our electrophysiological experiments provide new and important data about the electrophysiological properties of nonmodulated and respiratory-modulated RVLM presympathetic neurons in the intact sympathetic and respiratory networks and after synaptic blockade. Based on the in situ patch-clamp recordings, the results show that the respiratory-modulated RVLM presympathetic neurons constitute a heterogeneous neuronal population, in regards to the intrinsic electrophysiological properties, synaptic inputs, relation to $\mathrm{Cl}$ group and in the control of sympathetic outflow in response to a metabolic challenge produced by $\mathrm{CIH}$. There is experimental evidence pointing out to the involvement of RVLM presympathetic neurons in cardiovascular disorders (Han et al., 1998; Toney et al., 2010), including hypertension, but the cellular mechanisms underlying the possible changes in the excitability of presympathetic neurons are unknown. We are showing here for the first time that the respiratory-modulated RVLM presympathetic neurons (non-C1 neurons with post-I modulation) may contribute to the increased sympathetic outflow in $\mathrm{CIH}$ rats, which mecha- 
nisms involve enhanced respiratory synaptic inputs, probably from expiratory neurons. Therefore, the study of the cellular mechanisms involved in the central generation of respiratory-sympathetic coupling will have important implications for a better understanding of the medullary control of sympathetic activity in physiological and pathophysiological conditions.

\section{References}

Adrian ED, Bronk DW, Phillips G (1932) Discharges in mammalian sympathetic nerves. J Physiol 74:115-133. Medline

Allen AM, Guyenet PG (1993) Alpha 2-adrenoceptor-mediated inhibition of bulbospinal barosensitive cells of rat rostral medulla. Am J Physiol 265:R1065-R1075. Medline

Bachoo M, Polosa C (1985) Properties of a sympatho-inhibitory and vasodilator reflex evoked by superior laryngeal nerve afferents in the cat. J Physiol 364:183-198. Medline

Badra LJ, Cooke WH, Hoag JB, Crossman AA, Kuusela TA, Tahvanainen KU, Eckberg DL (2001) Respiratory modulation of human autonomic rhythms. Am J Physiol Heart Circ Physiol 280:H2674-2688. Medline

Barman SM, Gebber GL (1980) Sympathetic nerve rhythm of brain stem origin. Am J Physiol 239:R42-R47. Medline

Belugin S, Mifflin S (2005) Transient voltage-dependent potassium currents are reduced in NTS neurons isolated from renal wrap hypertensive rats. J Neurophysiol 94:3849-3859. CrossRef Medline

Brown HF, Kimura J, Noble D, Noble SJ, Taupignon A (1984) The ionic currents underlying pacemaker activity in rabbit sino-atrial node: experimental results and computer simulations. Proc R Soc Lond B Biol Sci 222:329-347. CrossRef Medline

Czyzyk-Krzeska MF, Trzebski A (1990) Respiratory-related discharge pattern of sympathetic nerve activity in the spontaneously hypertensive rat. J Physiol 426:355-368. Medline

Dampney RA (1994) Functional organization of central pathways regulating the cardiovascular system. Physiol Rev 74:323-364. CrossRef Medline

da Silva MP, Ventura RR, Varanda WA (2013) Hypertonicity increases NO production to modulate the firing rate of magnocellular neurons of the supraoptic nucleus of rats. Neuroscience 250:70-79. CrossRef Medline

Dembowsky K, McAllen RM (1990) Baroreceptor inhibition of subretrofacial neurons: evidence from intracellular recordings in the cat. Neurosci Lett 111:139-143. CrossRef Medline

Dempsey JA, Sheel AW, St Croix CM, Morgan BJ (2002) Respiratory influences on sympathetic vasomotor outflow in humans. Respir Physiol Neurobiol 130:3-20. CrossRef Medline

Dick TE, Hsieh YH, Morrison S, Coles SK, Prabhakar N (2004) Entrainment pattern between sympathetic and phrenic nerve activities in the Sprague-Dawley rat: hypoxia-evoked sympathetic activity during expiration. Am J Physiol Regul Integr Comp Physiol 286:R1121-R1128. CrossRef Medline

French CR, Sah P, Buckett KJ, Gage PW (1990) A voltage-dependent persistent sodium current in mammalian hippocampal neurons. J Gen Physiol 95:1139-1157. CrossRef Medline

Guyenet PG, Brown DL (1986) Nucleus paragigantocellularis lateralis and lumbar sympathetic discharge in the rat. Am J Physiol 250:R1081-R1094. Medline

Guyenet PG, Darnall RA, Riley TA (1990) Rostral ventrolateral medulla and sympathorespiratory integration in rats. Am J Physiol 259:R1063-R1074. Medline

Häbler HJ, Jänig W, Krummel M, Peters OA (1993) Respiratory modulation of the activity in postganglionic neurons supplying skeletal muscle and skin of the rat hindlimb. J Neurophysiol 70:920-930. Medline

Han YM, Chan YS, Lo KS, Wong TM (1998) Spontaneous activity and barosensitivity of the barosensitive neurons in the rostral ventrolateral medulla of hypertensive rats induced by transection of aortic depressor nerves. Brain Res 813:262-267. CrossRef Medline

Haselton JR, Guyenet PG (1989) Central respiratory modulation of medullary sympathoexcitatory neurons in rat. Am J Physiol 256:R739-R750. Medline

Hille B (2001) Ionic channels of excitable membranes, Ed 3. Sunderland, MA: Sinauer.

Kangrga IM, Loewy AD (1995) Whole-cell recordings from visualized C1 adrenergic bulbospinal neurons: ionic mechanisms underlying vasomotor tone. Brain Res 670:215-232. CrossRef Medline

Kanjhan R, Lipski J, Kruszewska B, Rong W (1995) A comparative study of pre-sympathetic and Botzinger neurons in the rostral ventrolateral medulla (RVLM) of the rat. Brain Res 699:19-32. CrossRef Medline

Koizumi H, Smith JC (2008) Persistent $\mathrm{Na}+$ and $\mathrm{K}+$-dominated leak currents contribute to respiratory rhythm generation in the pre-Botzinger complex in vitro. J Neurosci 28:1773-1785. CrossRef Medline

Lee S, Han TH, Sonner PM, Stern JE, Ryu PD, Lee SY (2008) Molecular characterization of T-type $\mathrm{Ca}\left({ }^{2+}\right)$ channels responsible for low threshold spikes in hypothalamic paraventricular nucleus neurons. Neuroscience 155:1195-1203. CrossRef Medline

Lipski J, Kanjhan R, Kruszewska B, Smith M (1995a) Barosensitive neurons in the rostral ventrolateral medulla of the rat in vivo: morphological properties and relationship to C1 adrenergic neurons. Neuroscience 69:601618. CrossRef Medline

Lipski J, Kanjhan R, Kruszewska B, Rong WF (1995b) Criteria for intracellular identification of pre-sympathetic neurons in the rostral ventrolateral medulla in the rat. Clin Exp Hypertens 17:51-65. CrossRef Medline

Lipski J, Kanjhan R, Kruszewska B, Rong WF, Smith M (1996) Presympathetic neurones in the rostral ventrolateral medulla of the rat: electrophysiology, morphology and relationship to adjacent neuronal groups. Acta Neurobiol Exp (Wars) 56:373-384. Medline

Liu S, Shipley MT (2008) Multiple conductances cooperatively regulate spontaneous bursting in mouse olfactory bulb external tufted cells. J Neurosci 28:1625-1639. CrossRef Medline

Llinás R, Yarom Y (1981) Electrophysiology of mammalian inferior olivary neurones in vitro. Different types of voltage-dependent ionic conductances. J Physiol 315:549-567. Medline

Luther JA, Tasker JG (2000) Voltage-gated currents distinguish parvocellular from magnocellular neurones in the rat hypothalamic paraventricular nucleus. J Physiol 523:193-209. Medline

Malpas SC (1998) The rhythmicity of sympathetic nerve activity. Prog Neurobiol 56:65-96. CrossRef Medline

McAllen RM (1987) Central respiratory modulation of subretrofacial bulbospinal neurones in the cat. J Physiol 388:533-545. Medline

McCormick DA, Pape HC (1990) Properties of a hyperpolarizationactivated cation current and its role in rhythmic oscillation in thalamic relay neurones. J Physiol 431:291-318. Medline

Miyawaki T, Pilowsky P, Sun QJ, Minson J, Suzuki S, Arnolda L, LlewellynSmith I, Chalmers J (1995) Central inspiration increases barosensitivity of neurons in rat rostral ventrolateral medulla. Am J Physiol 268:R909R918. Medline

Moraes DJ, Zoccal DB, Machado BH (2012a) Medullary respiratory network drives sympathetic overactivity and hypertension in rats submitted to chronic intermittent hypoxia. Hypertension 60:1374-1380. CrossRef Medline

Moraes DJ, Zoccal DB, Machado BH (2012b) Sympathoexcitation during chemoreflex active expiration is mediated by L-glutamate in the RVLM/ Botzinger complex of rats. J Neurophysiol 108:610-623. CrossRef Medline

Morrison SF, Milner TA, Reis DJ (1988) Reticulospinal vasomotor neurons of the rat rostral ventrolateral medulla: relationship to sympathetic nerve activity and the C1 adrenergic cell group. J Neurosci 8:1286-1301. Medline

Numao Y, Koshiya N, Gilbey MP, Spyer KM (1987) Central respiratory drive-related activity in sympathetic nerves of the rat: the regional differences. Neurosci Lett 81:279-284. CrossRef Medline

Paton JF (1996) A working heart-brainstem preparation of the mouse. J Neurosci Methods 65:63-68. CrossRef Medline

Pierrefiche O, Champagnat J, Richter DW (1995) Calcium-dependent conductances control neurones involved in termination of inspiration in cats. Neurosci Lett 184:101-104. CrossRef Medline

Reis DJ, Ruggiero DA, Morrison SF (1989) The C1 area of the rostral ventrolateral medulla oblongata. A critical brainstem region for control of resting and reflex integration of arterial pressure. Am J Hypertens 2:363S374S. Medline

Ruggiero DA, Cravo SL, Arango V, Reis DJ (1989) Central control of the circulation by the rostral ventrolateral reticular nucleus: anatomical substrates. Prog Brain Res 81:49-79. CrossRef Medline

Ruggiero DA, Cravo SL, Golanov E, Gomez R, Anwar M, Reis DJ (1994) Adrenergic and nonadrenergic spinal projections of a cardiovascularactive pressor area of medulla oblongata: quantitative topographic analysis. Brain Res 663:107-120. CrossRef Medline

Sirois JE, Lynch C 3rd, Bayliss DA (2002) Convergent and reciprocal mod- 
ulation of a leak $\mathrm{K}+$ current and $\mathrm{I}(\mathrm{h})$ by an inhalational anaesthetic and neurotransmitters in rat brainstem motoneurones. J Physiol 541:717729. CrossRef Medline

Sonner PM, Stern JE (2007) Functional role of A-type potassium currents in rat presympathetic PVN neurones. J Physiol 582:1219-1238. CrossRef Medline

Stern JE (2001) Electrophysiological and morphological properties of preautonomic neurones in the rat hypothalamic paraventricular nucleus. J Physiol 537:161-177. CrossRef Medline

Stornetta RL, Sevigny CP, Schreihofer AM, Rosin DL, Guyenet PG (2002) Vesicular glutamate transporter DNPI/VGLUT2 is expressed by both C1 adrenergic and nonaminergic presympathetic vasomotor neurons of the rat medulla. J Comp Neurol 444:207-220. CrossRef Medline

Sun MK, Reis DJ (1994) Hypoxia-activated $\mathrm{Ca}^{2+}$ currents in pacemaker neurones of rat rostral ventrolateral medulla in vitro. J Physiol 476:101116. Medline

Taylor EW, Jordan D, Coote JH (1999) Central control of the cardiovascular and respiratory systems and their interactions in vertebrates. Physiol Rev 79:855-916. Medline

Terui N, Saeki Y, Kumada M (1986) Barosensory neurons in the ventrolateral medulla in rabbits and their responses to various afferent inputs from peripheral and central sources. Jpn J Physiol 36:1141-1164. CrossRef Medline

Toney GM, Pedrino GR, Fink GD, Osborn JW (2010) Does enhanced respiratory-sympathetic coupling contribute to peripheral neural mechanisms of angiotensin II-salt hypertension? Exp Physiol 95:587-594. CrossRef Medline

Wang D, Schreurs BG (2006) Characteristics of IA currents in adult rabbit cerebellar Purkinje cells. Brain Res 1096:85-96. Medline

Williams JT, Bobker DH, Harris GC (1991) Synaptic potentials in locus coeruleus neurons in brain slices. Prog Brain Res 88:167-172. CrossRef Medline

Zagon A, Spyer KM (1996) Stimulation of aortic nerve evokes three different response patterns in neurons of rostral VLM of the rat. Am J Physiol 271:R1720-R1728. Medline

Zhou SY, Gebber GL, Zhong S, Barman SM (2002) Pathways involved in synchronization of sympathetic nerve discharge to lung inflation. Brain Res 931:107-116. CrossRef Medline

Zoccal DB, Simms AE, Bonagamba LG, Braga VA, Pickering AE, Paton JF, Machado BH (2008) Increased sympathetic outflow in juvenile rats submitted to chronic intermittent hypoxia correlates with enhanced expiratory activity. J Physiol 586:3253-3265. CrossRef Medline 